\section{Segurança do paciente no cuidado odontológico: revisão integrativa}

Patient safety in dental care: an integrative review

\author{
Seguridad del paciente en el cuidado \\ odontológico: revisión integradora
}

\author{
Claudia Dolores Trierweiler Sampaio de Oliveira \\ Corrêa 1 \\ Paulo Sousa 1,2 \\ Claudia Tartaglia Reis 3
}

\section{Resumo}

Eventos adversos constituem grave problema relacionado à qualidade do cuidado de saúde. A prática odontológica, por ser eminentemente invasiva e implicar contato íntimo e rotineiro com secreções, é potencialmente propícia à ocorrência desses eventos. Diversos estudos em segurança do paciente foram desenvolvidos nas duas últimas décadas, entretanto, em maior número no ambiente hospitalar, em função de sua complexidade organizacional, gravidade de casos, diversidade e especificidade de procedimentos. O objetivo foi identificar e explorar os estudos voltados à segurança do paciente odontológico. Foi realizada revisão integrativa da literatura com consulta ao MEDLINE via PubMed, Scopus via Portal Capes e ao Portal Regional da Biblioteca Virtual de Saúde, utilizando-se os termos segurança do paciente e odontologia nos idiomas inglês, espanhol e português a partir de 2000. Utilizouse o ciclo de pesquisa em segurança do paciente, proposto pela Organização Mundial da Saúde para classificar os estudos incluídos. Foram analisados 91 artigos. Os eventos adversos mais comuns foram relacionados às alergias, às infecções, ao atraso ou falha de diagnóstico e ao erro da técnica. Medidas para mitigar o problema apontaram para a necessidade de melhoria da comunicação, incentivo à notificação e procura por instrumentos para auxiliar a gestão do cuidado. Constatou-se carência de estudos de implementação e avaliação de impacto das propostas de melhoria. A Odontologia evoluiu no campo da segurança do paciente, mas ainda está aquém de transpor resultados para a prática, sendo importante envidar esforços para prevenir os eventos adversos nesta área.

Segurança do Paciente; Odontologia; Qualidade dos Cuidados de Saúde; Eventos Adversos

\author{
Correspondência \\ C. D. T. S. O. Corrêa \\ Rua Desembargador João Manoel de Carvalho 190, apto. 1001, \\ Vitória, ES 29057-630, Brasil. \\ cautrier1@gmail.com \\ 1 Escola Nacional de Saúde Pública, Universidade NOVA de \\ Lisboa, Lisboa, Portugal. \\ 2 Comprehensive Health Research Centre, Universidade NOVA \\ de Lisboa, Lisboa, Portugal. \\ 3 Secretaria Municipal de Saúde de Cataguases, Cataguases, \\ Brasil.
}




\section{Introdução}

A segurança do paciente é definida pela Organização Mundial da Saúde (OMS) como a "redução do risco de danos desnecessários relacionados aos cuidados de saúde para um mínimo aceitável" 1 (p. 21). Tem como foco a prevenção de eventos adversos (EA), definidos como os danos ao paciente decorrentes do cuidado de saúde e não da doença de base 1 .

A associação da temática à qualidade do cuidado é antiga 2. Porém, somente a partir das publicações To Err is Human: Building a Safer Health System 3 e Crossing the Quality Chasm: A New Health System for the 21st Century ${ }^{4}$ pelo Instituto de Medicina dos Estados Unidos, a magnitude do problema e suas consequências clínicas, econômicas e sociais ficaram expostas de uma forma mais evidente, sublinhando a grande distância entre a qualidade prometida daquela que efetivamente se concretizava.

Desde então, sob a liderança de organizações internacionais com particular destaque para a OMS, a segurança do paciente vem tomando corpo de conhecimento científico próprio ${ }^{5}$. Os estudos são crescentes e têm sido fundamentais para: (i) produzir conhecimento na área; (ii) disseminar informação; (iii) apoiar as tomadas de decisão; (iv) promover práticas baseadas em evidências; (v) monitorar e avaliar o impacto de medidas que visam a aumentar a segurança dos pacientes e melhorar a qualidade dos cuidados prestados 6 .

A maior parte dos estudos tem se desenvolvido no ambiente hospitalar, provavelmente em função de sua complexidade organizacional, gravidade dos casos, diversidade e especificidade de procedimentos 7 . Embora a atuação dos cirurgiões-dentistas seja majoritariamente ambulatorial, a prestação dos cuidados odontológicos é potencialmente propícia à ocorrência de EA. A prática é eminentemente invasiva, implica contato íntimo e rotineiro com secreções como saliva e sangue 8 , depende da habilidade do profissional e está em constante sujeição às possíveis emergências médicas 9,10.

Aliado a isso, o grande avanço tecnológico das últimas décadas, se por um lado propiciou maior agilidade e precisão aos diagnósticos e tratamentos 11, por outro, agregou maior complexidade ao atendimento e, por conseguinte, ao aumento do risco para a ocorrência de EA odontológicos 12.

Com base nesse cenário, o objetivo deste artigo foi identificar e explorar os estudos voltados à segurança do paciente odontológico. Conhecer os conteúdos discutidos nessas publicações é fundamental para destacar possíveis contribuições à prática e encontrar pontos de partidas passíveis de continuidade, imprescindíveis à compreensão do problema e à busca por melhorias da qualidade do cuidado e segurança do paciente nesse âmbito.

\section{Método}

Tratou-se de uma revisão integrativa da literatura norteada pela seguinte pergunta: "Como vem se desenvolvendo a pesquisa no campo da segurança do paciente odontológico e que contribuições os estudos apresentaram para a segurança do cuidado?". Para responder à questão foram realizadas buscas na base de dados MEDLINE via PubMed, Portal Regional da Biblioteca Virtual de Saúde (BVS Regional) e Scopus via Portal Capes, por estas reunirem a maior parte das publicações voltadas à área da saúde. Utilizou-se os termos do MeSH (Medical Subject Headings; https://www.ncbi.nlm.nih.gov/ mesh/) na língua inglesa: patient safety e dentistry em títulos e resumos (Quadro 1).

Foram estabelecidos como critérios de inclusão os artigos científicos nos idiomas inglês, espanhol e português, por conveniência dos autores e por representarem a grande maioria de publicações nessa área; que privilegiaram a segurança do paciente odontológico incluindo metodologias quantitativas, qualitativas, avaliativas, de intervenção, de reflexão, de análise documental e de revisão da literatura; o período de abrangência compreendeu entre 1o de janeiro de 2000 - ano da publicação do relatório To Err is Human: Building a Safer Health System - e 30 de junho de 2019.

Foram estabelecidos como critérios de exclusão os artigos que não contemplavam a segurança do paciente como abordagem central, tais como: os que focalizavam principalmente os aspectos legais, a saúde do trabalhador e a biossegurança; os artigos que envolveram outras profissões de saúde; editoriais, cartas, recomendações de órgãos/instituições, opiniões/comentários e entrevistas; e ainda, artigos duplicados que não apresentavam resumo e os inacessíveis. A leitura dos títulos e resumos foi realizada por duas pesquisadoras independentes e as dúvidas foram dirimidas por consenso entre ambas. 


\section{Quadro 1}

Estratégia de busca.

\begin{tabular}{|l|r|}
\hline PORTAL & BUSCA \\
\hline MEDLINE & "patient safety"[Title/Abstract] AND dentistry[Title/Abstract] AND (("2000/01/01”[PDAT] : \\
"2019/06/30"[PDAT]) AND (Portuguese[lang] OR Spanish[lang] OR English[lang]))
\end{tabular}

Fonte: elaboração própria.

Os estudos incluídos foram categorizados por ano, país de publicação, método e objetivo principal. Essa última categorização, realizada pelos autores, foi feita por aproximação com os componentes do ciclo investigativo proposto pela OMS 6 (Quadro 2); estudos descritivos que analisaram e discutiram conceitos da segurança do paciente e sua aplicação na Odontologia, mas que não permitiram enquadramento com os componentes do ciclo investigativo, foram classificados como outros.

\section{Resultados}

A busca nas três bases de dados identificou 315 artigos: 95 capturados pelo MEDLINE, 21 pela BVS Regional e 199 pela Scopus. Após a exclusão de 99 artigos (86 duplicados, 7 sem resumo disponível e 6 inacessíveis), 216 artigos foram selecionados para a leitura do título e resumo. Com base nas referências encontradas, 9 artigos foram capturados, o que complementou a amostra (Figura 1).

A amostra final foi composta por 91 artigos. Os países que se destacaram com maior número de publicações foram os Estados Unidos (39,3\%; $\mathrm{n}=33$ ) e Inglaterra (31\%; $\mathrm{n}=28)$; Brasil, Canadá, China, Chile, Escócia, Holanda, México, Paquistão, Suécia e Suíça apresentaram apenas 1 publicação no período (Tabela 1).

Tomando por base os objetivos dos estudos incluídos, categorizados pelos componentes do ciclo de pesquisa proposto pela OMS 6, observou-se que alguns deles abordaram mais de um componente. A maioria dedicou-se às fases iniciais: medir o dano $(28,6 \% ; \mathrm{n}=26)$; compreender as causas $(56 \%$; $\mathrm{n}=51)$; e identificar soluções $(32 \% ; \mathrm{n}=30)$. Oito estudos $(11 \%)$ tiveram por objetivo avaliar o impacto e dois $(2,2 \%)$ buscaram transpor a evidência em cuidados mais seguros (Quadro 3).

Quanto ao método utilizado, dos 91 estudos incluídos, 47,3\% ( $n=43)$ usou abordagens quantitativas, destacando-se os delineamentos seccionais e de revisão retrospectiva de prontuário. Apenas $8,8 \%$ $(\mathrm{n}=8)$ usaram delineamento qualitativo (Quadro 3).

\section{Discussão}

\section{O destaque dado à segurança do paciente odontológico}

As publicações sobre a segurança do paciente em Odontologia vêm aumentando em nível global, mesmo que timidamente; Inglaterra e Estados Unidos foram responsáveis pelo maior número de estudos incluídos. Uma atenção primária em saúde (APS) forte, como é o caso do contexto inglês, e o pioneirismo estadunidense em instituições engajadas na melhoria da qualidade do cuidado de saúde podem explicar esses achados. 
Quadro 2

Ciclo de pesquisa em segurança do paciente proposto pela Organização Mundial da Saúde (OMS).

\begin{tabular}{|c|c|c|}
\hline Componentes do ciclo & Fontes de dados e estratégias utilizadas & Métodos para a coleta de dados \\
\hline $\begin{array}{l}\text { 1. MEDIR O DANO: quantificar o número } \\
\text { de pacientes que sofrem dano ou morrem } \\
\text { a cada ano e de quais tipos de eventos } \\
\text { adversos, tais como erro de medicação, } \\
\text { infecções associadas aos cuidados de saúde, } \\
\text { cirurgias em local errado, entre outros }\end{array}$ & $\begin{array}{l}\text { Sistemas de notificação de incidentes, dados } \\
\text { administrativos, reclamações administrativas, } \\
\text { reclamações de má prática, reuniões de } \\
\text { morbimortalidade, auditorias, pesquisas } \\
\text { nacionais/regionais e prontuário do paciente }\end{array}$ & $\begin{array}{l}\text { Entrevistas com profissionais, a observação } \\
\text { direta e o monitoramento clínico }\end{array}$ \\
\hline $\begin{array}{l}\text { 2. COMPREENDER AS CAUSAS: identificar as } \\
\text { principais causas subjacentes a um evento } \\
\text { adverso }\end{array}$ & $\begin{array}{c}\text { Sistemas de notificação de incidentes, dados } \\
\text { administrativos, reclamações administrativas, } \\
\text { reclamações de má prática, reuniões de } \\
\text { morbimortalidade, auditorias ou pesquisas } \\
\text { nacionais ou regionais, e prontuário do } \\
\text { paciente }\end{array}$ & $\begin{array}{c}\text { Análise de causa raiz; inquéritos com } \\
\text { profissionais; análise de reclamações de má } \\
\text { prática; análise dos incidentes encontrados } \\
\text { em sistemas de notificação de incidentes; } \\
\text { observação direta }\end{array}$ \\
\hline $\begin{array}{l}\text { 3. IDENTIFICAR SOLUÇÕES: determinar } \\
\text { soluções efetivas para transformar o cuidado } \\
\text { de saúde mais seguro e reduzir o dano } \\
\text { ao paciente, comparado com o padrão de } \\
\text { cuidado presente }\end{array}$ & $\begin{array}{c}\text { Estudos de intervenção do tipo “antes } \\
\text { e depois"; ensaios clínicos controlados } \\
\text { randomizados, duplo cego; e randomização } \\
\text { por conglomerados }\end{array}$ & $\begin{array}{c}\text { As intervenções a testar ou aprimorar podem } \\
\text { se dar nos pacientes (p.ex.: tratamento } \\
\text { diferente), nos profissionais de saúde (p.ex.: } \\
\text { treinamento para melhorar a comunicação } \\
\text { da equipe), no ambiente de trabalho } \\
\text { (adaptações nos quartos para prevenção } \\
\text { de queda dos pacientes) ou no sistema } \\
\text { (alterações em um sistema de prescrição } \\
\text { eletrônica) }\end{array}$ \\
\hline $\begin{array}{l}\text { 4. AVALIAR O IMPACTO: avaliar a efetividade } \\
\text { de soluções na realidade dos serviços de } \\
\text { saúde em termos de: impacto, aceitabilidade } \\
\text { e capacidade de oferta }\end{array}$ & $\begin{array}{l}\text { Estudos que medem a frequência do dano, } \\
\text { a prevalência no cuidado apropriado, } \\
\text { avalia mudanças na prática decorrentes de } \\
\text { aprendizado, e a cultura de segurança do } \\
\text { paciente }\end{array}$ & $\begin{array}{c}\text { Os estudos podem ser direcionados aos } \\
\text { pacientes, profissionais de saúde, ambiente } \\
\text { de trabalho ou ao sistema }\end{array}$ \\
\hline $\begin{array}{l}\text { 5. TRANSPOR A EVIDÊNCIA EM CUIDADOS } \\
\text { MAIS SEGUROS: compreender como } \\
\text { os resultados da pesquisa podem ser } \\
\text { transpostos para a prática }\end{array}$ & $\begin{array}{l}\text { Resumir a evidência; identificar barreiras } \\
\text { locais à implementação; compreender o } \\
\text { contexto; medir o desempenho; garantir que } \\
\text { todos os pacientes recebam a intervenção }\end{array}$ & - \\
\hline
\end{tabular}

Fonte: adaptado de Caldas et al. ${ }^{6}$.

Especificidades da área podem apontar motivos para o baixo número de estudos: (i) procedimentos, em geral, menos invasivos que os médico-cirúrgicos, consequentemente, propensos a danos menos graves; (ii) as complicações odontológicas muitas vezes são atendidas em emergências hospitalares e o cirurgião-dentista não toma conhecimento do fato; (iii) grande parte dos atendimentos acontece no setor privado e/ou em consultórios individualizados, e o temor pelo afastamento da clientela pode limitar a explicitação do dano; e (iv) menor familiaridade com o tema nestes locais do que no ambiente hospitalar, historicamente mais afeito às campanhas, aos cursos e ao maior controle dos EA 9,13.

Entretanto, se há especificidades que podem explicar o afastamento em relação à temática, outras estabelecem desafios ao exercício da profissão que deveriam estimular a realização de estudos. Sob esse aspecto, destaca-se a predominância de procedimentos cirúrgicos e suas complicações, como sangramentos e infecções; a exposição constante à radiação ionizante; a necessidade de estar atento ao histórico de saúde dos pacientes 10 . 
Figura 1

Fluxo de seleção do estudo.
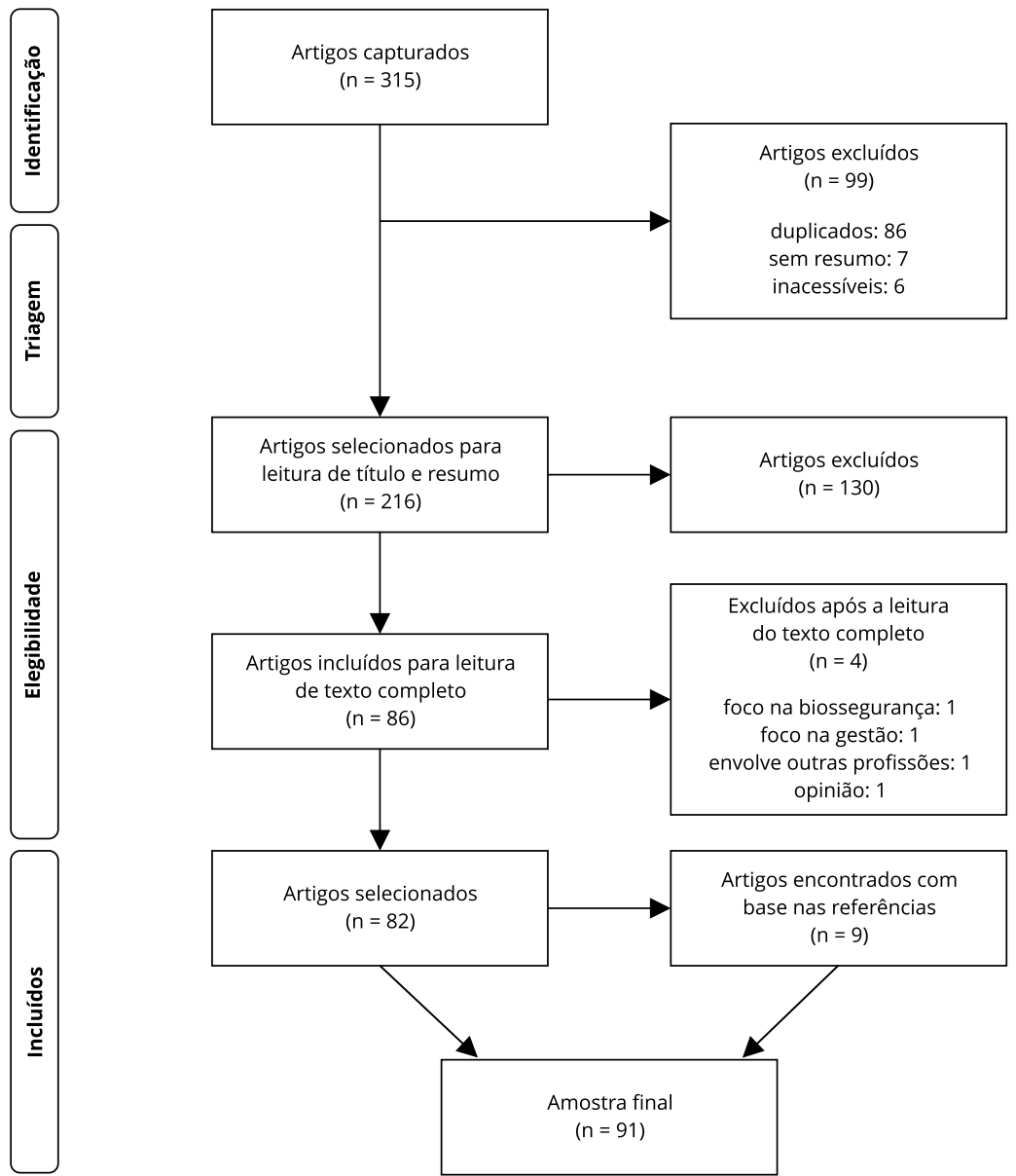

Observou-se uma tendência semelhante entre os estudos da área de segurança do paciente odontológico e os da segurança do paciente em geral 14,15 no que diz respeito às fontes e técnicas adotadas. Os estudos iniciais, de caráter exploratório, buscaram fazer um paralelo entre a Odontologia e a segurança do paciente 9,10,16,17,18,19,20; estes vêm dando lugar a abordagens mais específicas 21,22, sugerindo maior inserção da Odontologia na multidisciplinariedade que a temática da segurança do paciente requer.

\section{A magnitude do problema e a compreensão de suas causas}

Enquanto os primeiros estudos em segurança do paciente buscaram medir incidência/prevalência dos EA para conhecer a magnitude do problema 6, na Odontologia os estudos iniciais foram destinados, para além de medir a sua frequência, a compreender as suas causas, suscitando reflexão acerca dos desafios inerentes às especificidades da prática odontológica.

Na perspectiva de medir a incidência/prevalência dos danos, os estudos 12,21,23,24,25,26,27,28,29,30,31, $32,33,34,35,36,37,38,39,40,41,42,43$ trouxeram achados que vão desde complicações por anestesia local/sedação, lesões produzidas em língua e lábios, até a perda de dentes por exodontia trocada, lesões oculares 
Tabela 1

Estudos por país e ano de publicação.

\begin{tabular}{|c|c|c|c|c|c|c|c|c|c|c|c|c|c|}
\hline País de publicação & 2005 & 2008 & 2010 & 2011 & 2012 & 2013 & 2014 & 2015 & 2016 & 2017 & 2018 & 2019 * & Total \\
\hline Argentina & & & & & & & & 1 & & & & 1 & 2 \\
\hline Brasil & & & & & & & & & & 1 & & & 1 \\
\hline Canadá & & & & & & & 1 & & & & & & 1 \\
\hline Colômbia & & & & & & & & 1 & & 4 & & & 5 \\
\hline China & & & & & & & & & & & & 1 & 1 \\
\hline Chile & & & & & & & & & & 1 & & & 1 \\
\hline Dinamarca & & & & 1 & & & & 1 & & & & & 2 \\
\hline Escócia & & & & & & 1 & & & & & & & 1 \\
\hline Espanha & & & 1 & 2 & & 1 & 2 & & & & & & 6 \\
\hline Estados Unidos & 1 & 1 & 1 & 1 & & 3 & 4 & 5 & 4 & 4 & 9 & & 33 \\
\hline Holanda & & & & & & & & & & 1 & & & 1 \\
\hline Índia & & & & & & & & 1 & & 1 & & & 2 \\
\hline Inglaterra & & & & & 2 & 4 & 4 & 5 & 3 & 3 & 3 & 4 & 28 \\
\hline México & & & & & & & & & 1 & & & & 1 \\
\hline Nova Zelândia & & & & & 1 & & & 2 & & & & & 3 \\
\hline Paquistão & & & & & & & & & & & 1 & & 1 \\
\hline Suécia & & & & & & & 1 & & & & & & 1 \\
\hline Suíça & & & & & & & & & & & 1 & & 1 \\
\hline Total & 1 & 1 & 2 & 4 & 3 & 9 & 12 & 16 & 8 & 15 & 14 & 6 & 91 \\
\hline
\end{tabular}

Fonte: elaboração própria.

* Até junho.

\section{Quadro 3}

Características dos estudos incluídos.

\begin{tabular}{|c|c|c|c|c|}
\hline Estudo (Ano) & $\begin{array}{c}\text { País da } \\
\text { publicação }\end{array}$ & $\begin{array}{l}\text { Objetivos categorizados } \\
\text { com base no ciclo da } \\
\text { pesquisa proposto pela } \\
\text { OMS }\end{array}$ & Método & $\begin{array}{l}\text { Principais resultados/ } \\
\text { recomendações }\end{array}$ \\
\hline $\begin{array}{l}\text { Gluskin et al. } 55 \\
(2005)\end{array}$ & Estados Unidos & Identificar soluções & Estudo de série de casos & $\begin{array}{c}\text { Formula e recomenda protocolo para } \\
\text { aumentar a segurança no uso de } \\
\text { dispositivo ultrassônico em terapia } \\
\text { endodôntica }\end{array}$ \\
\hline $\begin{array}{l}\text { Leong et al. } 66 \\
\text { (2008) }\end{array}$ & Estados Unidos & Compreender as causas & $\begin{array}{c}\text { Estudo quantitativo, } \\
\text { observacional, seccional }\end{array}$ & $\begin{array}{l}\text { Destaca a necessidade do } \\
\text { envolvimento da liderança e sugere } \\
\text { a implantação de um sistema de } \\
\text { notificação de incidentes }\end{array}$ \\
\hline $\begin{array}{l}\text { Mendonça et al. } 50 \\
\text { (2010) }\end{array}$ & Estados Unidos & Compreender as causas & $\begin{array}{c}\text { Estudo descritivo, } \\
\text { observacional }\end{array}$ & $\begin{array}{c}\text { Evidencia que a presença do } \\
\text { farmacêutico e o treinamento } \\
\text { contínuo dos dentistas contribuem } \\
\text { para a prescrição segura }\end{array}$ \\
\hline
\end{tabular}




\begin{tabular}{|c|c|c|c|c|}
\hline Estudo (Ano) & $\begin{array}{c}\text { País da } \\
\text { publicação }\end{array}$ & $\begin{array}{l}\text { Objetivos categorizados } \\
\text { com base no ciclo da } \\
\text { pesquisa proposto pela } \\
\text { OMS }\end{array}$ & Método & $\begin{array}{l}\text { Principais resultados/ } \\
\text { recomendações }\end{array}$ \\
\hline $\begin{array}{l}\text { Perea-Pérez et } \\
\text { al. } 16(2010)\end{array}$ & Espanha & Outros & $\begin{array}{l}\text { Análise temática } \\
\text { conjuntural }\end{array}$ & $\begin{array}{c}\text { Faz uma descrição do que é a } \\
\text { segurança do paciente e sua interação } \\
\text { com a Odontologia }\end{array}$ \\
\hline $\begin{array}{l}\text { Noguerado et al. } 94 \\
\text { (2011) }\end{array}$ & Espanha & Identificar soluções & $\begin{array}{l}\text { Descritivo, observacional, } \\
\text { revisão retrospectiva de } \\
\text { prontuário }\end{array}$ & $\begin{array}{l}\text { Faz uma revisão dos fármacos mais } \\
\text { utilizados em Odontologia e propõe } \\
\text { um guia de prescrição segura para } \\
\text { grávidas e lactantes }\end{array}$ \\
\hline Tan 58 (2011) & Estados Unidos & Identificar soluções & $\begin{array}{l}\text { Estudo quantitativo, } \\
\text { observacional, seccional }\end{array}$ & $\begin{array}{c}\text { Postula que a simulação ajuda a } \\
\text { melhorar a confiança do profissional } \\
\text { no gerenciamento de situações de } \\
\text { crise }\end{array}$ \\
\hline $\begin{array}{l}\text { Perea-Pérez et } \\
\text { al. } 13(2011)\end{array}$ & Espanha & Transpor evidências & $\begin{array}{c}\text { Construção de } \\
\text { instrumento de gestão/ } \\
\text { proposta de intervenção }\end{array}$ & $\begin{array}{l}\text { Apresenta um plano de } \\
\text { gerenciamento de riscos para } \\
\text { atendimento odontológico }\end{array}$ \\
\hline $\begin{array}{l}\text { Perea-Pérez et } \\
\text { al. } 82(2011)\end{array}$ & Dinamarca & Identificar soluções & $\begin{array}{l}\text { Adaptação transcultural } \\
\text { de instrumento }\end{array}$ & $\begin{array}{c}\text { Disponibiliza uma lista de verificação } \\
\text { para a cirurgia odontológica }\end{array}$ \\
\hline $\begin{array}{l}\text { Yamalik \& Perea- } \\
\text { Pérez }{ }^{9}(2012)\end{array}$ & Inglaterra & Outros & $\begin{array}{l}\text { Estudo reflexivo- } \\
\text {-conceitual }\end{array}$ & $\begin{array}{l}\text { Descreve os fundamentos da } \\
\text { segurança do paciente e a inserção } \\
\text { odontológica na área }\end{array}$ \\
\hline $\begin{array}{l}\text { Thusu et al. } 12 \\
\text { (2012) }\end{array}$ & Inglaterra & $\begin{array}{c}\text { Medir o dano; compreender } \\
\text { as causas }\end{array}$ & $\begin{array}{l}\text { Estudo descritivo/análise } \\
\text { quantitativa da base } \\
\text { de dados do sistema } \\
\text { nacional de notificação de } \\
\text { incidentes }\end{array}$ & $\begin{array}{l}\text { Descreve incidentes de segurança: } \\
\text { lesões aos tecidos moles; emergência } \\
\text { médica; inalação/ingestão; reação } \\
\text { adversa a medicamentos; extração } \\
\text { errada }\end{array}$ \\
\hline $\begin{array}{l}\text { Guzmán-Álvarez et } \\
\text { al. } 98 \text { (2012) }\end{array}$ & Nova Zelândia & Compreender as causas & $\begin{array}{l}\text { Estudo quantitativo } \\
\text { seccional }\end{array}$ & $\begin{array}{c}\text { Identifica as lacunas de conhecimento } \\
\text { em Farmacologia que podem } \\
\text { afetar a segurança do paciente nas } \\
\text { universidades }\end{array}$ \\
\hline $\begin{array}{l}\text { Kalenderian et } \\
\text { al. } 23 \text { (2013) }\end{array}$ & Estados Unidos & Medir o dano & $\begin{array}{l}\text { Descritivo, observacional, } \\
\text { revisão retrospectiva de } \\
\text { prontuários }\end{array}$ & $\begin{array}{c}\text { Propõe e testa rastreadores de EA } \\
\text { odontológicos para a revisão de } \\
\text { prontuários }\end{array}$ \\
\hline $\begin{array}{l}\text { Yamalik \& Van } \\
\text { Dijk } 67 \text { (2013) }\end{array}$ & Inglaterra & Compreender as causas & $\begin{array}{l}\text { Estudo quantitativo, } \\
\text { observacional, seccional }\end{array}$ & $\begin{array}{c}\text { Enforca as regulamentações nacionais } \\
\text { sobre segurança do paciente como } \\
\text { essenciais para a temática }\end{array}$ \\
\hline $\begin{array}{l}\text { Knepil et al. } 78 \\
\text { (2013) }\end{array}$ & Escócia & $\begin{array}{l}\text { Identificar soluções; avaliar } \\
\text { o impacto }\end{array}$ & $\begin{array}{l}\text { Estudo quali-quantitativo } \\
\text { com aplicação de } \\
\text { entrevista }\end{array}$ & $\begin{array}{l}\text { Identifica a marcação cirúrgica } \\
\text { que mais agradou a pacientes e } \\
\text { profissionais. Sugere adaptação no } \\
\text { checklist da OMS para exodontias }\end{array}$ \\
\hline $\begin{array}{l}\text { Mettes et al. } 24 \\
\text { (2013) }\end{array}$ & Inglaterra & $\begin{array}{c}\text { Medir o dano; compreender } \\
\text { as causas }\end{array}$ & $\begin{array}{l}\text { Descritivo; observacional, } \\
\text { revisão retrospectiva de } \\
\text { prontuário }\end{array}$ & $\begin{array}{l}\text { Destaca os incidentes considerados } \\
\text { evitáveis relacionados ao tratamento, } \\
\text { ao diagnóstico e à comunicação }\end{array}$ \\
\hline $\begin{array}{l}\text { Hiivala et al. } 103 \\
\text { (2013) }\end{array}$ & Inglaterra & Identificar soluções & $\begin{array}{c}\text { Estudo quantitativo, } \\
\text { observacional, seccional }\end{array}$ & $\begin{array}{c}\text { Enfatiza a importância do } \\
\text { envolvimento da chefia, de se cumprir } \\
\text { orientações já disponíveis e das } \\
\text { notificações de incidentes }\end{array}$ \\
\hline
\end{tabular}

(continua) 
Quadro 3 (continuação)

\begin{tabular}{|c|c|c|c|c|}
\hline Estudo (Ano) & $\begin{array}{c}\text { País da } \\
\text { publicação }\end{array}$ & $\begin{array}{l}\text { Objetivos categorizados } \\
\text { com base no ciclo da } \\
\text { pesquisa proposto pela } \\
\text { OMS }\end{array}$ & Método & $\begin{array}{l}\text { Principais resultados/ } \\
\text { recomendações }\end{array}$ \\
\hline $\begin{array}{l}\text { Hiivala et al. } 25 \\
\text { (2013) }\end{array}$ & Inglaterra & $\begin{array}{c}\text { Medir o dano; compreender } \\
\text { as causas }\end{array}$ & $\begin{array}{c}\text { Estudo quantitativo, } \\
\text { observacional, seccional }\end{array}$ & $\begin{array}{l}\text { Refere que os EA predominantes } \\
\text { foram em prótese, endodontia e } \\
\text { cirurgia. Lista fatores contribuintes }\end{array}$ \\
\hline $\begin{array}{l}\text { Perea-Pérez et } \\
\text { al. } 57 \text { (2013) }\end{array}$ & Espanha & Identificar soluções & $\begin{array}{l}\text { Revisão documental com } \\
\text { proposta de intervenção }\end{array}$ & $\begin{array}{c}\text { Propõe avaliação de riscos no cuidado } \\
\text { odontológico para os portadores de } \\
\text { deficiência }\end{array}$ \\
\hline Lee et al. 26 (2013) & Estados Unidos & Medir o dano & $\begin{array}{l}\text { Estudo descritivo, } \\
\text { observacional. Análise } \\
\text { retrospectiva de base de } \\
\text { dados }\end{array}$ & $\begin{array}{l}\text { Identifica associação entre } \\
\text { mortalidade e procedimentos } \\
\text { odontológicos pediátricos sob sedação }\end{array}$ \\
\hline $\begin{array}{l}\text { Donaldson \& } \\
\text { Touger-Decker } 53 \\
\text { (2013) }\end{array}$ & Estados Unidos & Compreender as causas & Revisão da literatura & $\begin{array}{l}\text { Aponta os riscos na interação } \\
\text { de suplementos dietéticos e } \\
\text { medicamentos prescritos em } \\
\text { Odontologia }\end{array}$ \\
\hline $\begin{array}{l}\text { Perea-Pérez et } \\
\text { al. } 27 \text { (2014) }\end{array}$ & Espanha & $\begin{array}{c}\text { Medir o dano; compreender } \\
\text { as causas }\end{array}$ & $\begin{array}{c}\text { Estudo descritivo, } \\
\text { observacional. Revisão } \\
\text { retrospectiva de } \\
\text { demandas judiciais } \\
\end{array}$ & $\begin{array}{l}\text { Identifica como dano mais } \\
\text { comum a perda de dentes. As } \\
\text { especialidades predominantes foram: } \\
\text { implantodontia, endodontia e cirurgia }\end{array}$ \\
\hline Raja et al. 59 (2014) & Estados Unidos & Compreender as causas & $\begin{array}{l}\text { Estudo quantitativo } \\
\text { seccional com pré- e } \\
\text { pós-teste }\end{array}$ & $\begin{array}{l}\text { Aponta a necessidade de incluir o } \\
\text { preparo para a comunicação de EA na } \\
\text { formação acadêmica }\end{array}$ \\
\hline $\begin{array}{l}\text { Ashley et al. } 100 \\
\text { (2014) }\end{array}$ & Inglaterra & Identificar soluções & $\begin{array}{l}\text { Artigo reflexivo, análise } \\
\text { temática conjuntural }\end{array}$ & $\begin{array}{l}\text { Apresenta diversas modalidades de } \\
\text { auditoria clínica como estratégia para } \\
\text { qualidade do cuidado e segurança do } \\
\text { paciente }\end{array}$ \\
\hline $\begin{array}{l}\text { Pemberton et al. } 64 \\
\text { (2014) }\end{array}$ & Inglaterra & $\begin{array}{l}\text { Identificar soluções; avaliar } \\
\text { o impacto }\end{array}$ & $\begin{array}{c}\text { Análise temática } \\
\text { conjuntural, revisão } \\
\text { documental com proposta } \\
\text { de intervenção }\end{array}$ & $\begin{array}{l}\text { Descreve o desenvolvimento de um } \\
\text { painel expositivo de segurança do } \\
\text { paciente como fator de incentivo } \\
\text { à cultura de segurança e foco nas } \\
\text { questões-chave para a segurança do } \\
\text { paciente }\end{array}$ \\
\hline $\begin{array}{l}\text { Ramoni et al. } 68 \\
\text { (2014) }\end{array}$ & Estados Unidos & $\begin{array}{l}\text { Compreender as causas; } \\
\text { identificar soluções }\end{array}$ & $\begin{array}{l}\text { Estudo quantitativo, } \\
\text { descritivo seccional }\end{array}$ & $\begin{array}{l}\text { Mede a cultura como um meio } \\
\text { de acionar um círculo virtuoso de } \\
\text { melhoria, e destaca as diferentes } \\
\text { percepções entre gestores e } \\
\text { profissionais }\end{array}$ \\
\hline $\begin{array}{l}\text { Speers \& } \\
\text { McCulloch } 17 \text { (2014) }\end{array}$ & Canadá & Identificar soluções & $\begin{array}{l}\text { Análise temática } \\
\text { conjuntural }\end{array}$ & $\begin{array}{l}\text { Recomenda a implantação de } \\
\text { treinamento baseado no Crew } \\
\text { Resource Management à prática } \\
\text { odontológica }\end{array}$ \\
\hline $\begin{array}{l}\text { Bailey et al. } 10 \\
(2014)\end{array}$ & Inglaterra & Outros & $\begin{array}{l}\text { Revisão de literatura e } \\
\text { análise conjuntural }\end{array}$ & $\begin{array}{c}\text { Explica e reforça a relevância da } \\
\text { segurança do paciente para a } \\
\text { Odontologia primária e sugere áreas } \\
\text { para pesquisas futuras }\end{array}$ \\
\hline
\end{tabular}

(continua) 


\begin{tabular}{|c|c|c|c|c|}
\hline Estudo (Ano) & $\begin{array}{c}\text { País da } \\
\text { publicação }\end{array}$ & $\begin{array}{l}\text { Objetivos categorizados } \\
\text { com base no ciclo da } \\
\text { pesquisa proposto pela } \\
\text { OMS }\end{array}$ & Método & $\begin{array}{l}\text { Principais resultados/ } \\
\text { recomendações }\end{array}$ \\
\hline $\begin{array}{l}\text { Beedis et al. } 87 \\
(2014)\end{array}$ & Inglaterra & $\begin{array}{l}\text { Identificar soluções; avaliar } \\
\text { o impacto }\end{array}$ & $\begin{array}{l}\text { Estudo de série de } \\
\text { casos com proposta de } \\
\text { intervenção }\end{array}$ & $\begin{array}{c}\text { Elabora uma lista de verificação para } \\
\text { avaliação e encaminhamento dos } \\
\text { pacientes com trismo }\end{array}$ \\
\hline $\begin{array}{l}\text { Díaz-Flores-García } \\
\text { et al. } 89 \text { (2014) }\end{array}$ & Espanha & Identificar soluções & $\begin{array}{l}\text { Estudo de adaptação de } \\
\text { instrumento }\end{array}$ & $\begin{array}{l}\text { Apresenta uma lista de verificação } \\
\text { para tratamento endodôntico }\end{array}$ \\
\hline $\begin{array}{l}\text { Donaldson \& } \\
\text { Touger-Decker } 54 \\
\text { (2014) }\end{array}$ & Estados Unidos & Compreender as causas & Revisão da literatura & $\begin{array}{l}\text { Aponta os riscos na interação de } \\
\text { suplementos vitamínicos/minerais } \\
\text { com medicamentos prescritos em } \\
\text { Odontologia }\end{array}$ \\
\hline $\begin{array}{l}\text { Donaldson et al. } 52 \\
\text { (2014) }\end{array}$ & Estados Unidos & Compreender as causas & Revisão da literatura & $\begin{array}{l}\text { Aponta os riscos de interação entre } \\
\text { os medicamentos prescritos em } \\
\text { Odontologia e medicamentos para } \\
\text { emagrecer }\end{array}$ \\
\hline $\begin{array}{l}\text { Jonsson \& Gabre } 28 \\
\text { (2014) }\end{array}$ & Suécia & Medir o dano & $\begin{array}{l}\text { Estudo quantitativo, } \\
\text { descritivo, seccional }\end{array}$ & $\begin{array}{c}\text { Reconhece a dificuldade de notificar } \\
\text { incidentes de segurança, mas enfatiza } \\
\text { a necessidade de notificações } \\
\text { por todos os envolvidos, inclusive } \\
\text { pacientes }\end{array}$ \\
\hline $\begin{array}{l}\text { Piccinni et al. } 21 \\
\text { (2015) }\end{array}$ & Dinamarca & Medir o dano & $\begin{array}{l}\text { Estudo quantitativo, } \\
\text { analítico, do tipo } \\
\text { caso-controle }\end{array}$ & $\begin{array}{l}\text { Sugere que a prilocaína e/ou a } \\
\text { articaína podem estar associadas a } \\
\text { um aumento do risco de parestesia }\end{array}$ \\
\hline $\begin{array}{l}\text { Akifuddin \& } \\
\text { Khatoon } 29 \text { (2015) }\end{array}$ & Índia & $\begin{array}{c}\text { Medir o dano; compreender } \\
\text { as causas }\end{array}$ & $\begin{array}{l}\text { Estudo quantitativo, } \\
\text { descritivo, com aplicação } \\
\text { do método Seis Sigma }\end{array}$ & $\begin{array}{l}\text { Descreve as complicações mais } \\
\text { recorrentes na anestesia local. A } \\
\text { metodologia Seis Sigma ajudou a } \\
\text { melhorar o atendimento }\end{array}$ \\
\hline O'Brien 18 (2015) & Inglaterra & Outros & $\begin{array}{l}\text { Análise temática } \\
\text { conjuntural/reflexiva }\end{array}$ & $\begin{array}{c}\text { Descreve parâmetros e conceitos } \\
\text { da segurança do paciente utilizados } \\
\text { na Medicina que são aplicáveis à } \\
\text { Odontologia }\end{array}$ \\
\hline $\begin{array}{l}\text { Christiani et al. } 30 \\
\text { (2015) }\end{array}$ & Colômbia & $\begin{array}{c}\text { Medir o dano; compreender } \\
\text { as causas }\end{array}$ & $\begin{array}{l}\text { Estudo observacional, } \\
\text { descritivo, análise } \\
\text { prospectiva de } \\
\text { notificações voluntárias }\end{array}$ & $\begin{array}{c}\text { Evidencia que a maior parte dos erros } \\
\text { é recorrente. Recomenda fortalecer } \\
\text { a cultura de segurança do paciente } \\
\text { como forma de reduzir a ocorrência } \\
\text { de EA }\end{array}$ \\
\hline $\begin{array}{l}\text { Christiani \& } \\
\text { Rocha } 47 \text { (2015) }\end{array}$ & Argentina & Compreender as causas & $\begin{array}{l}\text { Estudo quantitativo, } \\
\text { descritivo, seccional }\end{array}$ & $\begin{array}{l}\text { Aponta a necessidade de fortalecer } \\
\text { a cultura de segurança e afirma que } \\
\text { os cirurgiões-dentistas são pouco } \\
\text { informados sobre a temática }\end{array}$ \\
\hline $\begin{array}{l}\text { Perea-Pérez et } \\
\text { al. } 96 \text { (2015) }\end{array}$ & Estados Unidos & $\begin{array}{l}\text { Compreender as causas; } \\
\text { identificar soluções }\end{array}$ & $\begin{array}{l}\text { Revisão retrospectiva de } \\
\text { demandas judiciais }\end{array}$ & $\begin{array}{l}\text { Conclui que a maioria dos EA } \\
\text { advém de um pequeno número } \\
\text { de causas e a implementação de } \\
\text { procedimentos básicos podem reduzi- } \\
\text { los significativamente }\end{array}$ \\
\hline
\end{tabular}

(continua) 
Quadro 3 (continuação)

\begin{tabular}{|c|c|c|c|c|}
\hline Estudo (Ano) & $\begin{array}{c}\text { País da } \\
\text { publicação }\end{array}$ & $\begin{array}{l}\text { Objetivos categorizados } \\
\text { com base no ciclo da } \\
\text { pesquisa proposto pela } \\
\text { OMS }\end{array}$ & Método & $\begin{array}{l}\text { Principais resultados/ } \\
\text { recomendações }\end{array}$ \\
\hline Bailey 48 (2015) & Inglaterra & $\begin{array}{l}\text { Compreender as causas; } \\
\text { identificar soluções }\end{array}$ & Qualitativo; grupo focal & $\begin{array}{l}\text { Apresenta sugestões de melhoria da } \\
\text { segurança do paciente com base na } \\
\text { expertise dos cirurgiões-dentistas }\end{array}$ \\
\hline $\begin{array}{l}\text { Obadan et al. } 31 \\
(2015)\end{array}$ & Estados Unidos & Medir o dano & Revisão da literatura & $\begin{array}{l}\text { Refere que foram encontrados } 270 \text { EA } \\
\text { em } 182 \text { publicações }\end{array}$ \\
\hline $\begin{array}{l}\text { Nelson \& Xu } 65 \\
(2015)\end{array}$ & Nova Zelândia & $\begin{array}{l}\text { Compreender as causas; } \\
\text { identificar soluções }\end{array}$ & $\begin{array}{l}\text { Análise temática } \\
\text { conjuntural/reflexiva }\end{array}$ & $\begin{array}{l}\text { Destaca a necessidade da seleção } \\
\text { cuidadosa de procedimentos e de } \\
\text { fortalecer a cultura de segurança } \\
\text { para reduzir os riscos envolvidos na } \\
\text { sedação pediátrica }\end{array}$ \\
\hline $\begin{array}{l}\text { Bailey et al. } 83 \\
(2015)\end{array}$ & Inglaterra & Identificar soluções & Revisão da literatura & $\begin{array}{l}\text { Apresenta a adoção de listas de } \\
\text { verificação cirúrgica como as únicas } \\
\text { intervenções em Odontologia que } \\
\text { evidenciam a redução de EA }\end{array}$ \\
\hline $\begin{array}{l}\text { Bennett et al. } 80 \\
\text { (2015) }\end{array}$ & Estados Unidos & $\begin{array}{l}\text { Compreender as causas; } \\
\text { identificar soluções }\end{array}$ & $\begin{array}{c}\text { Análise temática } \\
\text { conjuntural/reflexiva }\end{array}$ & $\begin{array}{l}\text { Propõe que o atendimento deve } \\
\text { obedecer a diretrizes preestabelecidas } \\
\text { para a seleção do anestésico e } \\
\text { monitoramento do paciente }\end{array}$ \\
\hline $\begin{array}{l}\text { Martín-Cameán } \\
\text { et al. } 56 \text { (2015) }\end{array}$ & Nova Zelândia & Compreender as causas & Revisão da literatura & $\begin{array}{l}\text { Avalia que aparelhos ortodônticos } \\
\text { podem levar à liberação de íons } \\
\text { metálicos que comprometam a } \\
\text { segurança do paciente }\end{array}$ \\
\hline $\begin{array}{l}\text { Bagg \& Welbury } 19 \\
\text { (2015) }\end{array}$ & Inglaterra & Compreender as causas & $\begin{array}{l}\text { Análise temática } \\
\text { conjuntural/reflexiva }\end{array}$ & $\begin{array}{l}\text { Refere que a qualidade do cuidado e } \\
\text { a segurança do paciente devem ser } \\
\text { colocadas acima de todos os outros } \\
\text { objetivos. Enfatiza a importância da } \\
\text { centralização do paciente no cuidado }\end{array}$ \\
\hline $\begin{array}{l}\text { Hiivala et al. } 101 \\
\text { (2015) }\end{array}$ & Inglaterra & Compreender as causas & $\begin{array}{l}\text { Estudo quantitativo com } \\
\text { revisão retrospectiva de } \\
\text { demandas judiciais }\end{array}$ & $\begin{array}{l}\text { Destaca que mais da metade dos } \\
\text { registros das reclamações dos } \\
\text { pacientes/familiares revelaram } \\
\text { danos físicos ou potenciais riscos à } \\
\text { segurança do paciente }\end{array}$ \\
\hline $\begin{array}{l}\text { Donaldson \& } \\
\text { Goodchild } 51 \text { (2015) }\end{array}$ & Estados Unidos & Compreender as causas & Revisão da literatura & $\begin{array}{l}\text { Aponta que elevadas concentrações } \\
\text { de açúcar no medicamento podem } \\
\text { aumentar o risco para a ocorrência } \\
\text { de cárie }\end{array}$ \\
\hline $\begin{array}{l}\text { Hebballi et al. } 32 \\
\text { (2015) }\end{array}$ & Estados Unidos & Medir o dano & $\begin{array}{l}\text { Estudo quantitativo, com } \\
\text { análise retrospectiva } \\
\text { de base de dados de } \\
\text { notificação de EA }\end{array}$ & $\begin{array}{c}\text { Apresenta o mau uso ou o mau } \\
\text { funcionamento dos dispositivos } \\
\text { dentários como fator contribuinte } \\
\text { ao EA. As notificações de EA } \\
\text { desempenham um papel } \\
\text { fundamental na melhoria do acesso } \\
\text { dos odontólogos às informações } \\
\text { sobre segurança de dispositivos } \\
\text { odontológicos }\end{array}$ \\
\hline
\end{tabular}

(continua) 


\begin{tabular}{|c|c|c|c|c|}
\hline Estudo (Ano) & $\begin{array}{c}\text { País da } \\
\text { publicação }\end{array}$ & $\begin{array}{l}\text { Objetivos categorizados } \\
\text { com base no ciclo da } \\
\text { pesquisa proposto pela } \\
\text { OMS }\end{array}$ & Método & $\begin{array}{l}\text { Principais resultados/ } \\
\text { recomendações }\end{array}$ \\
\hline $\begin{array}{l}\text { Hiivala et al. } 33 \\
(2016)\end{array}$ & Inglaterra & $\begin{array}{c}\text { Medir o dano; compreender } \\
\text { as causas }\end{array}$ & $\begin{array}{l}\text { Estudo quantitativo, com } \\
\text { análise retrospectiva } \\
\text { de base de dados de } \\
\text { notificação de EA }\end{array}$ & $\begin{array}{l}\text { Classificou a maioria dos EA como } \\
\text { evitável, de elevada gravidade, com } \\
\text { danos permanentes ou duradouros e } \\
\text { relacionados ao procedimento e/ou } \\
\text { diagnósticos clínicos }\end{array}$ \\
\hline $\begin{array}{l}\text { Nenad et al. } 88 \\
(2016)\end{array}$ & Estados Unidos & $\begin{array}{l}\text { Identificar soluções; avaliar } \\
\text { o impacto }\end{array}$ & $\begin{array}{l}\text { Estudo de avaliação } \\
\text { de intervenção/ } \\
\text { método misto/grupo de } \\
\text { intervenção e controle } \\
\text { não randomizado }\end{array}$ & $\begin{array}{c}\text { Não encontrou associação positiva } \\
\text { entre o uso da lista de verificação e a } \\
\text { taxa de erro e repetição da tomada } \\
\text { radiográfica }\end{array}$ \\
\hline $\begin{array}{l}\text { Maramaldi et al. } 34 \\
(2016)\end{array}$ & Estados Unidos & $\begin{array}{c}\text { Medir o dano; compreender } \\
\text { as causas }\end{array}$ & $\begin{array}{c}\text { Estudo qualitativo/ } \\
\text { grupo focal/entrevistas } \\
\text { aprofundadas }\end{array}$ & $\begin{array}{l}\text { Apresenta uma listagem de EA em } \\
\text { Odontologia e suas possíveis causas }\end{array}$ \\
\hline $\begin{array}{l}\text { Renton \& } \\
\text { Sabbah } 44 \text { (2016) }\end{array}$ & Inglaterra & $\begin{array}{c}\text { Medir o dano; compreender } \\
\text { as causas }\end{array}$ & $\begin{array}{c}\text { Análise retrospectiva da } \\
\text { base do sistema nacional } \\
\text { de notificações de EA }\end{array}$ & $\begin{array}{l}\text { Descreve e avalia never events } \\
\text { relacionados à Odontologia }\end{array}$ \\
\hline Castillo 20 (2016) & México & Identificar soluções & $\begin{array}{l}\text { Análise temática } \\
\text { conjuntural/reflexiva }\end{array}$ & $\begin{array}{c}\text { Descreve as medidas que podem } \\
\text { beneficiar o cuidado odontológico } \\
\text { em conformidade com as diretrizes e } \\
\text { metas da OMS }\end{array}$ \\
\hline $\begin{array}{l}\text { Donaldson \& } \\
\text { Goodchild } 93 \text { (2016) }\end{array}$ & Estados Unidos & Identificar soluções & $\begin{array}{l}\text { Análise temática } \\
\text { conjuntural }\end{array}$ & $\begin{array}{c}\text { Revisa os princípios farmacocinéticos } \\
\text { e farmacodinâmicos de antagonistas } \\
\text { farmacológicos para ajudar a mitigar } \\
\text { emergências médicas induzidas } \\
\text { por medicamentos prescritos em } \\
\text { Odontologia } \\
\end{array}$ \\
\hline $\begin{array}{l}\text { Renton \& Master } 75 \\
\text { (2016) }\end{array}$ & Inglaterra & Compreender as causas & $\begin{array}{l}\text { Análise temática } \\
\text { conjuntural }\end{array}$ & $\begin{array}{l}\text { Fornece uma revisão das } \\
\text { complexidades dos sistemas e } \\
\text { procedimentos existentes em } \\
\text { relação à segurança do paciente em } \\
\text { Odontologia }\end{array}$ \\
\hline $\begin{array}{l}\text { Ensaldo-Carrasco } \\
\text { et al. } 35 \text { (2016) }\end{array}$ & Estados Unidos & Medir o dano & Revisão da literatura & $\begin{array}{l}\text { Apresenta os principais tipos de EA, } \\
\text { porém não consegue estimativas } \\
\text { confiáveis sobre a frequência dos } \\
\text { mesmos }\end{array}$ \\
\hline $\begin{array}{l}\text { Tokede et al. } 36 \\
\text { (2017) }\end{array}$ & Estados Unidos & Medir o dano & $\begin{array}{l}\text { Estudo quantitativo, } \\
\text { descritivo, com revisão } \\
\text { retrospectiva de } \\
\text { prontuário }\end{array}$ & $\begin{array}{l}\text { Estima a incidência de } 3 \text { EA por } 100 \\
\text { pacientes/ano. Reforça a necessidade } \\
\text { de entender a epidemiologia básica } \\
\text { dos EA, tanto em termos de sua } \\
\text { frequência quanto à diversidade de } \\
\text { populações acometidas }\end{array}$ \\
\hline Ali et al. 69 (2017) & Índia & Compreender as causas & $\begin{array}{l}\text { Estudo quantitativo, } \\
\text { seccional }\end{array}$ & $\begin{array}{l}\text { Avalia diversos aspectos da cultura } \\
\text { organizacional entre odontólogos, e } \\
\text { destaca a comunicação e redução do } \\
\text { estresse como fatores contribuintes à } \\
\text { melhoria da qualidade e da segurança }\end{array}$ \\
\hline
\end{tabular}




\begin{tabular}{|c|c|c|c|c|}
\hline Estudo (Ano) & $\begin{array}{l}\text { País da } \\
\text { publicação }\end{array}$ & $\begin{array}{l}\text { Objetivos categorizados } \\
\text { com base no ciclo da } \\
\text { pesquisa proposto pela } \\
\text { OMS }\end{array}$ & Método & $\begin{array}{l}\text { Principais resultados/ } \\
\text { recomendações }\end{array}$ \\
\hline $\begin{array}{l}\text { Black \& Bowie } 45 \\
\text { (2017) }\end{array}$ & Inglaterra & $\begin{array}{c}\text { Medir o dano; compreender } \\
\text { as causas }\end{array}$ & $\begin{array}{l}\text { Estudo quali-quantitativo, } \\
\text { incluindo revisão de } \\
\text { literatura, análises } \\
\text { descritivas e qualitativas, } \\
\text { painel de especialistas }\end{array}$ & $\begin{array}{c}\text { Apresenta uma lista de } 9 \text { never } \\
\text { events que cobrem uma série de } \\
\text { questões potencialmente graves em } \\
\text { Odontologia }\end{array}$ \\
\hline $\begin{array}{l}\text { Corrêa \& } \\
\text { Mendes } 37 \text { (2017) }\end{array}$ & Brasil & Medir o dano & $\begin{array}{c}\text { Estudo qualitativo, revisão } \\
\text { de literatura, painel de } \\
\text { especialistas }\end{array}$ & $\begin{array}{l}\text { Propõe um conjunto de } 14 \\
\text { rastreadores para a detecção de EA } \\
\text { odontológicos }\end{array}$ \\
\hline $\begin{array}{l}\text { Cullingham et al. } 79 \\
\text { (2017) }\end{array}$ & Inglaterra & $\begin{array}{l}\text { Compreender as causas; } \\
\text { identificar soluções }\end{array}$ & $\begin{array}{c}\text { Análise temática } \\
\text { conjuntural/reflexiva }\end{array}$ & $\begin{array}{l}\text { Destaca a importância das notificações } \\
\text { de incidentes e análises de causa } \\
\text { raiz para auxiliar a compreensão dos } \\
\text { fatores contribuintes à exodontia } \\
\text { trocada }\end{array}$ \\
\hline $\begin{array}{l}\text { Hussein et al. } 95 \\
\text { (2017) }\end{array}$ & Holanda & Identificar soluções & $\begin{array}{l}\text { Estudo qualitativo, com } \\
\text { análise documental e } \\
\text { painel de especialistas }\end{array}$ & $\begin{array}{c}\text { Propõe indicadores de qualidade } \\
\text { na prescrição de antibióticos em } \\
\text { Odontologia }\end{array}$ \\
\hline $\begin{array}{l}\text { Ibrahim et al. } 102 \\
\text { (2017) }\end{array}$ & Inglaterra & Compreender as causas & $\begin{array}{l}\text { Estudo quantitativo } \\
\text { seccional }\end{array}$ & $\begin{array}{c}\text { Revela que os pacientes } \\
\text { demonstraram atitudes adequadas } \\
\text { em relação ao controle de infecções, } \\
\text { mas necessitam maior conhecimento } \\
\text { sobre a questão e práticas a serem } \\
\text { adotadas }\end{array}$ \\
\hline $\begin{array}{l}\text { Skaar \& } \\
\text { O'Connor } 92 \text { (2017) }\end{array}$ & Estados Unidos & Compreender as causas & $\begin{array}{l}\text { Estudo quantitativo } \\
\text { seccional }\end{array}$ & $\begin{array}{l}\text { Aponta a necessidade de aumentar o } \\
\text { conhecimento do cirurgião-dentista } \\
\text { quantos aos EA relacionados à } \\
\text { medicação em idosos }\end{array}$ \\
\hline $\begin{array}{l}\text { Osegueda-Espinosa } \\
\text { et al. } 38 \text { (2017) }\end{array}$ & Estados Unidos & $\begin{array}{c}\text { Medir o dano; compreender } \\
\text { as causas }\end{array}$ & $\begin{array}{l}\text { Estudo quantitativo } \\
\text { seccional }\end{array}$ & $\begin{array}{c}\text { Aponta para a necessidade de adoção } \\
\text { de estratégias para reduzir riscos e } \\
\text { promover a cultura de segurança nas } \\
\text { escolas de Odontologia }\end{array}$ \\
\hline $\begin{array}{l}\text { Huertas et al. } 39 \\
(2017)\end{array}$ & Colômbia & $\begin{array}{c}\text { Medir o dano; compreender } \\
\text { as causas }\end{array}$ & $\begin{array}{l}\text { Estudo observacional, } \\
\text { descritivo, com análise } \\
\text { de notificação de EA e } \\
\text { revisão retrospectiva de } \\
\text { prontuário }\end{array}$ & $\begin{array}{l}\text { Identifica } 43 \text { EA, dentre os quais, } \\
42 \text { são classificados como evitáveis. } \\
\text { Evidencia uma cultura de segurança } \\
\text { frágil e destaca a necessidade de } \\
\text { treinamento para a adesão a práticas } \\
\text { seguras, aquisição de habilidades } \\
\text { de comunicação e centralidade do } \\
\text { cuidado no paciente }\end{array}$ \\
\hline $\begin{array}{l}\text { Vila-Sierra et al. } 77 \\
\text { (2017) }\end{array}$ & Colômbia & $\begin{array}{l}\text { Compreender as causas; } \\
\text { avaliar o impacto }\end{array}$ & $\begin{array}{l}\text { Estudo descritivo } \\
\text { seccional }\end{array}$ & $\begin{array}{l}\text { Identifica avanços na adesão do } \\
\text { programa de segurança do paciente } \\
\text { odontológico. Sugere auditorias } \\
\text { periódicas para identificar a adesão a } \\
\text { guias e protocolos }\end{array}$ \\
\hline
\end{tabular}

(continua) 


\begin{tabular}{|c|c|c|c|c|}
\hline Estudo (Ano) & $\begin{array}{c}\text { País da } \\
\text { publicação }\end{array}$ & $\begin{array}{l}\text { Objetivos categorizados } \\
\text { com base no ciclo da } \\
\text { pesquisa proposto pela } \\
\text { OMS }\end{array}$ & Método & $\begin{array}{l}\text { Principais resultados/ } \\
\text { recomendações }\end{array}$ \\
\hline $\begin{array}{l}\text { Rivera-Mendoza et } \\
\text { al. } 97 \text { (2017) }\end{array}$ & Chile & Compreender as causas & $\begin{array}{l}\text { Estudo de caso com } \\
\text { análise de causa-raiz }\end{array}$ & $\begin{array}{l}\text { Apresenta o passo a passo para } \\
\text { proceder à análise de causa-raiz e } \\
\text { suas recomendações para melhoria }\end{array}$ \\
\hline $\begin{array}{l}\text { Renouard et. } 76 \\
\text { (2017) }\end{array}$ & Estados Unidos & Compreender as causas & $\begin{array}{l}\text { Análise temática } \\
\text { conjuntural/reflexiva. }\end{array}$ & $\begin{array}{l}\text { Aponta a necessidade da introdução } \\
\text { do conceito de "fatores humanos" } \\
\text { na formação acadêmica e vivência } \\
\text { profissional; recomenda a notificação } \\
\text { e análise de erros para melhorar } \\
\text { a segurança para profissionais e } \\
\text { pacientes }\end{array}$ \\
\hline $\begin{array}{l}\text { Pesántez Alvarado } \\
\text { et al. } 40 \text { (2017) }\end{array}$ & Colômbia & Medir o dano & $\begin{array}{l}\text { Estudo observacional, } \\
\text { descritivo, com revisão } \\
\text { retrospectiva de } \\
\text { prontuário }\end{array}$ & $\begin{array}{c}\text { Identifica } 74 \text { complicações cirúrgicas, } \\
\text { das quais } 66 \text { se relacionam à } \\
\text { exodontia; classificou } 11 \text { EA (9 } \\
\text { evitáveis e } 2 \text { não evitáveis) }\end{array}$ \\
\hline $\begin{array}{l}\text { Pérez Gómez et } \\
\text { al. } 41 \text { (2017) }\end{array}$ & Colômbia & $\begin{array}{c}\text { Medir o dano; compreender } \\
\text { as causas }\end{array}$ & $\begin{array}{l}\text { Estudo observacional, } \\
\text { descritivo, com revisão } \\
\text { retrospectiva de } \\
\text { prontuário }\end{array}$ & $\begin{array}{c}\text { Estima a incidência de } 6,1 \% \text { de EA nos } \\
\text { pacientes atendidos. Desses, 58\% são } \\
\text { classificados como evitáveis. Enfatiza a } \\
\text { importância da notificação }\end{array}$ \\
\hline $\begin{array}{l}\text { Madarati et al. } 90 \\
(2018)\end{array}$ & Suíça & Identificar soluções & $\begin{array}{l}\text { Estudo quantitativo, } \\
\text { descritivo, seccional }\end{array}$ & $\begin{array}{c}\text { Refere o isolamento absoluto na } \\
\text { terapia endodôntica como bem } \\
\text { aceito pelos pacientes, sendo a sua } \\
\text { segurança a vantagem mais referida }\end{array}$ \\
\hline $\begin{array}{l}\text { Robinson et al. } 104 \\
\text { (2018) }\end{array}$ & Estados Unidos & $\begin{array}{c}\text { Identificar soluções; } \\
\text { avaliar o impacto; transpor } \\
\text { evidências }\end{array}$ & $\begin{array}{l}\text { Estudo qualitativo/painel } \\
\text { de especialistas }\end{array}$ & $\begin{array}{c}\text { Desenvolve, apresenta e implementa } \\
\text { um procedimento padronizado } \\
\text { para obtenção do consentimento } \\
\text { informado }\end{array}$ \\
\hline $\begin{array}{l}\text { Schmitt et al. } 84 \\
(2018)\end{array}$ & Estados Unidos & $\begin{array}{l}\text { Identificar soluções; avaliar } \\
\text { o impacto }\end{array}$ & $\begin{array}{l}\text { Ensaio clínico } \\
\text { randomizado }\end{array}$ & $\begin{array}{c}\text { Elabora e valida listas de verificação } \\
\text { para cirurgias odontológicas } \\
\text { ambulatoriais }\end{array}$ \\
\hline $\begin{array}{l}\text { Robert \& Patel } 81 \\
(2018)\end{array}$ & Estados Unidos & Identificar soluções & $\begin{array}{l}\text { Análise temática } \\
\text { conjuntural }\end{array}$ & $\begin{array}{l}\text { Descreve os aspectos necessários } \\
\text { aos planos de gerenciamento de } \\
\text { emergências médicas em consultórios } \\
\text { odontológicos }\end{array}$ \\
\hline $\begin{array}{l}\text { Al Sweleh et al. } 70 \\
(2018)\end{array}$ & Estados Unidos & Compreender as causas & $\begin{array}{l}\text { Estudo quantitativo, } \\
\text { descritivo, seccional }\end{array}$ & $\begin{array}{l}\text { Avalia a cultura de segurança } \\
\text { entre professores de Odontologia; } \\
\text { recomenda ênfase na melhoria da } \\
\text { comunicação, fortalecimento do } \\
\text { trabalho em equipe e respostas não } \\
\text { punitivas frente ao erro }\end{array}$ \\
\hline $\begin{array}{l}\text { Parker et al. } 22 \\
(2018)\end{array}$ & Estados Unidos & Avaliar o impacto & $\begin{array}{l}\text { Revisão da literatura/ } \\
\text { metanálise }\end{array}$ & $\begin{array}{l}\text { Avalia benefícios e danos associados } \\
\text { à capnografia no monitoramento da } \\
\text { sedação moderada. Relata que a sua } \\
\text { adoção reduz o risco de desenvolver } \\
\text { hipoxemia, indicando seu uso } \\
\text { rotineiramente }\end{array}$ \\
\hline
\end{tabular}

(continua) 
Quadro 3 (continuação)

\begin{tabular}{|c|c|c|c|c|}
\hline Estudo (Ano) & $\begin{array}{l}\text { País da } \\
\text { publicação }\end{array}$ & $\begin{array}{l}\text { Objetivos categorizados } \\
\text { com base no ciclo da } \\
\text { pesquisa proposto pela } \\
\text { OMS }\end{array}$ & Método & $\begin{array}{l}\text { Principais resultados/ } \\
\text { recomendações }\end{array}$ \\
\hline $\begin{array}{l}\text { Al Blaihed et al. } 62 \\
(2018)\end{array}$ & Inglaterra & Compreender as causas & $\begin{array}{l}\text { Estudo quantitativo, } \\
\text { descritivo seccional }\end{array}$ & $\begin{array}{l}\text { Descreve a percepção dos } \\
\text { supervisores clínicos sobre a } \\
\text { notificação de incidentes cometidos } \\
\text { por alunos. A barreira identificada } \\
\text { como mais comum foi uma possível } \\
\text { relação negativa entre supervisor/ } \\
\text { aluno }\end{array}$ \\
\hline $\begin{array}{l}\text { Mahmood et al. } 99 \\
\text { (2018) }\end{array}$ & Paquistão & Compreender as causas & $\begin{array}{l}\text { Estudo quantitativo, } \\
\text { descritivo seccional }\end{array}$ & $\begin{array}{c}\text { Aponta lacunas de conhecimento } \\
\text { acadêmico em Farmacologia como } \\
\text { fatores contribuintes à ocorrência de } \\
\text { erros de prescrição }\end{array}$ \\
\hline Nainar 74 (2018) & Estados Unidos & Compreender as causas & $\begin{array}{c}\text { Análise temática } \\
\text { conjuntural/reflexiva }\end{array}$ & $\begin{array}{c}\text { Descreve o comprometimento físico e } \\
\text { emocional do profissional diretamente } \\
\text { envolvido nas ocorrências de EA e } \\
\text { enfatiza a necessidade de apoiá-lo }\end{array}$ \\
\hline $\begin{array}{l}\text { Wright et al. } 85 \\
(2018)\end{array}$ & Inglaterra & $\begin{array}{l}\text { Identificar soluções; avaliar } \\
\text { o impacto }\end{array}$ & $\begin{array}{l}\text { Adaptação de } \\
\text { instrumento com uso de } \\
\text { abordagem qualitativa, } \\
\text { painel de especialistas }\end{array}$ & $\begin{array}{c}\text { Apresenta uma lista de verificação } \\
\text { cirúrgica e recomenda treinamento } \\
\text { para seu uso, visando ao cuidado } \\
\text { centrado no paciente para mitigar } \\
\text { potenciais consequências de erros } \\
\text { humanos }\end{array}$ \\
\hline $\begin{array}{l}\text { Chew et al. } 71 \\
(2018)\end{array}$ & Estados Unidos & Compreender as causas & $\begin{array}{l}\text { Estudo qualitativo } \\
\text { utilizando entrevista }\end{array}$ & $\begin{array}{l}\text { Recomenda a promoção da cultura de } \\
\text { segurança nas escolas de formação, } \\
\text { além do fomento de adesão a } \\
\text { regulamentos e diretrizes clínicas }\end{array}$ \\
\hline $\begin{array}{l}\text { Al-Surimi et al. } 61 \\
(2018)\end{array}$ & Inglaterra & Compreender as causas & $\begin{array}{l}\text { Estudo quantitativo } \\
\text { descritivo seccional }\end{array}$ & $\begin{array}{c}\text { Assinala maior preocupação com } \\
\text { a segurança do paciente entre } \\
\text { estudantes de Odontologia do sexo } \\
\text { feminino. Sugere incentivos ao } \\
\text { trabalho em equipe e liderança. Infere } \\
\text { que a percepção dos acadêmicos } \\
\text { em relação à cultura de segurança } \\
\text { melhora ao longo da experiência } \\
\text { clínica }\end{array}$ \\
\hline $\begin{array}{l}\text { Ensaldo-Carrasco } \\
\text { et al. } 46(2018)\end{array}$ & Estados Unidos & $\begin{array}{c}\text { Medir o dano; compreender } \\
\text { as causas }\end{array}$ & $\begin{array}{l}\text { Estudo qualitativo com } \\
\text { painel de especialistas }\end{array}$ & $\begin{array}{l}\text { Apresenta uma lista de never events } \\
\text { para o cuidado odontológico na } \\
\text { atenção primária }\end{array}$ \\
\hline $\begin{array}{l}\text { Kalenderian et } \\
\text { al. } 42 \text { (2018) }\end{array}$ & Estados Unidos & Medir o dano & $\begin{array}{l}\text { Estudo de revisão e } \\
\text { consenso por meio de } \\
\text { painel de especialistas }\end{array}$ & $\begin{array}{l}\text { Desenvolve rastreadores eletrônicos } \\
\text { para a detecção de EA odontológicos } \\
\text { e mede o seu desempenho. } \\
\text { Identificaram no estudo-piloto os } \\
\text { principais EA: dor, infecção e danos } \\
\text { nos tecidos }\end{array}$ \\
\hline
\end{tabular}

(continua) 


\begin{tabular}{|c|c|c|c|c|}
\hline Estudo (Ano) & $\begin{array}{c}\text { País da } \\
\text { publicação }\end{array}$ & $\begin{array}{c}\text { Objetivos categorizados } \\
\text { com base no ciclo da } \\
\text { pesquisa proposto pela } \\
\text { OMS }\end{array}$ & Método & $\begin{array}{l}\text { Principais resultados/ } \\
\text { recomendações }\end{array}$ \\
\hline $\begin{array}{l}\text { Cheng et al. } 72 \\
\text { (2019) }\end{array}$ & China & Compreender as causas & $\begin{array}{l}\text { Estudo quantitativo } \\
\text { descritivo seccional }\end{array}$ & $\begin{array}{c}\text { Conclui que os resultados da avaliação } \\
\text { da cultura de segurança podem } \\
\text { orientar intervenções para melhorias } \\
\text { na segurança do paciente }\end{array}$ \\
\hline $\begin{array}{l}\text { Christiani \& } \\
\text { Rocha } 86 \text { (2019) }\end{array}$ & Argentina & Identificar soluções & $\begin{array}{c}\text { Adaptação transcultural } \\
\text { de instrumento }\end{array}$ & $\begin{array}{l}\text { Propõe uma lista de verificação para } \\
\text { melhorar a segurança do paciente } \\
\text { durante as intervenções cirúrgicas }\end{array}$ \\
\hline $\begin{array}{l}\text { Asmarz et al. } 91 \\
\text { (2019) }\end{array}$ & Inglaterra & $\begin{array}{l}\text { Compreender as causas; } \\
\text { identificar soluções }\end{array}$ & Estudo de caso & $\begin{array}{c}\text { Reforça a necessidade de se cumprir } \\
\text { protocolo de utilização do lençol de } \\
\text { borracha para prevenir a aspiração de } \\
\text { corpo estranho }\end{array}$ \\
\hline Stahl et al. 43 (2019) & Inglaterra & $\begin{array}{c}\text { Medir o dano; compreender } \\
\text { as causas }\end{array}$ & $\begin{array}{c}\text { Análise de notificações } \\
\text { de EA }\end{array}$ & $\begin{array}{l}\text { Identifica como EA mais frequentes } \\
\text { a anestesia no local errado e o } \\
\text { tratamento do dente errado. A falha } \\
\text { na comunicação e na adesão de } \\
\text { protocolo foram os principais fatores } \\
\text { contribuintes }\end{array}$ \\
\hline Choi et al. 73 (2019) & Inglaterra & Compreender as causas & $\begin{array}{l}\text { Estudo quantitativo } \\
\text { descritivo seccional }\end{array}$ & $\begin{array}{c}\text { Demonstra a influência do ambiente } \\
\text { organizacional na segurança do } \\
\text { paciente }\end{array}$ \\
\hline $\begin{array}{l}\text { Palmer et al. } 60 \\
\text { (2019) }\end{array}$ & Inglaterra & Compreender as causas & $\begin{array}{l}\text { Estudo qualitativo com } \\
\text { grupo focal }\end{array}$ & $\begin{array}{l}\text { Recomenda a introdução do ensino da } \\
\text { segurança do paciente nos primeiros } \\
\text { anos da graduação em Odontologia }\end{array}$ \\
\hline
\end{tabular}

EA: eventos adversos; OMS: Organização Mundial da Saúde.

Fonte: elaboração própria.

e mesmo o óbito; incidentes relacionados a alergias, infecções, atraso ou falha de diagnóstico, falha no procedimento, entre outros. Porém, como bem colocaram Ensaldo-Carrasco et al. 35, as evidências obtidas ainda são consideradas frágeis para fornecer estimativas confiáveis sobre a incidência e frequência desses eventos.

No esforço de caracterizar never events odontológicos, definidos como incidentes que resultaram em óbito ou deficiência significativa para o paciente e que nunca deveriam ocorrer ${ }^{44}$, três estudos utilizaram metodologia qualitativa e trouxeram classificações distintas 44,45,46. A proposta de Renton \& Sabbah 44 tomou por base a lista de never events do Serviço Nacional de Saúde do Reino Unido (NHS), atualizada em 2015/2016. A de Black \& Bowie 45 refinou 507 sugestões de 250 cirurgiões-dentistas por meio do método Delphi modificado. Ensaldo-Carrasco et al. 46 também usaram o método Delphi modificado, mas se apoiaram na literatura para criar a lista inicial de never events que foi refinada por 41 especialistas de países diversos.

Para investigar a evitabilidade dos EA, Pérez Gómez et al. 41 analisaram 595 prontuários encontrando 36 EA; destes, 21 (58\%) foram considerados evitáveis. O estudo de Mettes et al. 24 identificou um total de 46 EA odontológicos, dos quais 39\% foram considerados evitáveis. Esses autores inferiram que, apesar do percentual relativamente baixo de EA evitáveis sugerir segurança na prática odontológica, a baixa qualidade dos registros somada à subjetividade do conceito de evitabilidade podem 
implicar subestimação da medida. Tal situação suscita uma análise crítica, em especial quando se contrasta os estudos citados com outros dois: o de Huertas et al. 39 em que das 227 queixas de pacientes analisadas, 43 foram classificadas como EA, 42 (98\%) evitáveis; e o de Pesántez Alvarado et al. 40 em que, dentre 1.062 histórias clínicas analisadas de pacientes que passaram por procedimentos cirúrgicos, 11 EA foram identificados, sendo 9 (82\%) classificados como evitáveis.

Com enfoque na compreensão das causas, dentre os fatores contribuintes ao cuidado inseguro, foram identificados os erros de diagnóstico e/ou de planejamento, a comunicação ineficaz, a falha na execução de procedimentos, a baixa adesão a protocolos e a anamnese insuficiente 25,33,39,43,47,48. Esses fatores foram descritos como falhas latentes ou ativas. Obadan et al. 31 analisaram hipoteticamente a ingestão acidental de corpos estranhos e apontaram como possibilidade de falhas latentes a baixa capacidade clínica, o treinamento inadequado e a manutenção deficiente de equipamentos; e como falha ativa a proteção inadequada das vias aéreas do paciente.

Os EA decorrentes do circuito de medicamentos, que incluem a prescrição, a dispensação e a administração destes, são amplamente evidenciados na literatura científica. No contexto da APS, a prescrição medicamentosa foi referida como uma das principais causas para a ocorrência de EA 49, o que vai ao encontro do objeto de um dos primeiros estudos incluídos: a prescrição medicamentosa em Odontologia 50.

Estudos demonstraram a necessidade de atenção voltada ao uso de medicamentos e outras substâncias. $\mathrm{O}$ açúcar presente em muitos medicamentos pode atuar como fator coadjuvante da cárie, particularmente em pacientes com dificuldade de deglutição 51; medicamentos utilizados para perder peso 52, suplementos dietéticos 53 e vitamínicos 54 foram também destacados, sugerindo que o profissional considere estas condições a fim de elaborar uma proposta de intervenção segura, centrada no paciente.

Outra preocupação é a associação de EA às tecnologias empregadas no cuidado odontológico 55,56. Nessa linha, Hebballi et al. 32 analisaram os relatórios de incidentes com dispositivos sanitários notificados à Agência de Administração de Alimento e Drogas dos Estados Unidos (FDA) em 2011. Os resultados mostraram que, de um total de 1.978 .056 relatórios, $28.046(1,4 \%)$ foram associados aos dispositivos dentários. Uma parte (2.942) foi excluída por não fornecer informações adequadas. Dos relatórios analisados, 17.261 foram relacionados a lesões, 7.777 ao mau funcionamento do dispositivo e 66 ocasionaram óbitos. Desses, 52 estavam claramente associados ao dispositivo dentário.

É importante destacar que os fatores contribuintes não são associados somente ao paciente, mas aos prestadores do cuidado e ao ambiente de trabalho. Dentre os associados às características dos pacientes são exemplos: as incapacidades motoras e/ou mentais e as peculiaridades de crianças e idosos. Entre aqueles associados às condições de trabalho e ao profissional destacamos: os ambientes agitados que colaboram com distrações; a elevada rotatividade; a falta de habilidades oriundas da formação e capacitação do profissional; a visibilidade e a comunicação deficientes 57 .

O treinamento é essencial para lidar com problemas com os quais os profissionais podem vir a se deparar ao longo da vida laboral 58,59,60, sendo importante incorporar o tema da segurança do paciente desde os primeiros anos de formação 61 . Um estudo 39 realizado com estudantes de Odontologia apontou questões relacionadas a fatores humanos predisponentes ao EA, como a fadiga do operador, a falta de consciência dos riscos e as falhas nos encaminhamentos. Corroborando esses achados, Osegueda-Espinosa et al. 38 chamaram a atenção para a necessidade de supervisão mais ativa nos ambientes acadêmicos.

Ratifica-se a importância da formação do cirurgião-dentista para capacitá-lo a identificar urgências e situações que fogem ao seu controle, a fim de proceder a encaminhamentos adequados, como enfatizado por $\mathrm{Al}$ Blaihed et al. ${ }^{62}$. Nesse estudo, os autores descreveram dificuldades dos professores em notificar incidentes cometidos por alunos; observaram que, embora houvesse relatos verbais, estes não eram registrados por escrito, denotando uma frágil cultura de segurança local.

A cultura de segurança do paciente refere-se às crenças, valores e normas partilhados entre os profissionais, que também influenciam seu comportamento e suas ações 63 . No âmbito dessa revisão, estudos fizeram alusão ao tema $13,64,65$ ou o tiveram como central 47,61,66,67,68,69,70,71,72,73. Nos contextos estudados foram encontrados pontos positivos, como: a elevada percepção geral de segurança do paciente; o cuidado centrado no paciente; a busca pela efetividade e equidade dos cuidados; e a valorização do trabalho em equipe. As fragilidades descritas foram: a baixa notificação de incidentes 
e a escassez de treinamento, o acompanhamento deficiente do paciente e a falta de apoio da liderança à segurança do paciente.

É fundamental preocupar-se também com os fatores organizacionais, como falhas no ambiente físico, agendamento e gerenciamento de pacientes, linhas de responsabilidade e a influência de políticas 35. Uma pesquisa realizada com técnicos em higiene dental evidenciou que a percepção destes em relação à segurança do paciente é inversamente proporcional ao número de horas trabalhadas e ao número de pacientes atendidos 73 .

Há evidências de que profissionais envolvidos em EA podem sofrer emoções que afetam o seu desempenho e a sua saúde, podendo levar ao abuso de substâncias e à depressão ${ }^{74}$. O apoio da organização ao profissional envolvido em EA, também denominado "segunda vítima”, integra questões importantes para a segurança do cuidado. $\mathrm{O}$ apoio não punitivo frente à ocorrência de incidentes de segurança e EA, bem como a simplificação dos sistemas de notificação são medidas que auxiliam nesse caminho 70,75. Para permitir uma compreensão aprofundada do problema do EA, é necessário aliar o conhecimento técnico dos profissionais aos seus aspectos cognitivos e comportamentais 76 .

Por fim, a implantação de políticas e monitoramentos periódicos do cumprimento de diretrizes da prática clínica e protocolos de segurança 77 é necessária. A indisponibilidade de leis e/ou regulamentações nacionais relativas à segurança dos pacientes odontológicos aponta para uma baixa conscientização social do problema 67.

\section{As soluções identificadas e sua contribuição para a melhoria da segurança clínica}

Os estudos voltados para a segurança nos procedimentos cirúrgicos receberam destaque, possivelmente por sua natureza mais invasiva. Um deles 78 trouxe o processo de marcação do sítio cirúrgico como oportunidade de comunicação entre pacientes e profissionais, possibilitando reduzir a chance de erros como, por exemplo, a exodontia trocada, o que é uma grande preocupação 44,79.

A melhoria da comunicação suscitou o desenvolvimento de um quadro expositivo para o ambiente hospitalar. Nele, os profissionais lançavam os eventos inseguros ocorridos durante a rotina de atendimento odontológico, o que contribuiu para a discussão periódica de melhoria da qualidade realizada pela equipe 64 .

Para melhorar a segurança anestésica, o monitoramento adequado e uma equipe altamente treinada foram apontados como primordiais 80,81 . Além disso, uma revisão sistemática sugeriu a adição rotineira da capnografia ao monitoramento padrão de adultos durante a sedação moderada 22.

As listas de verificação foram consideradas eficazes na melhoria dos processos de trabalho, na otimização da comunicação e na redução dos níveis de estresse em cirurgias 78,81,82,83,84,85,86. Elas também se mostraram úteis no apoio ao diagnóstico do câncer 87 e para o fortalecimento da cultura de segurança 88 .

Para o tratamento endodôntico, além de uma lista de verificação ${ }^{89}$, foi proposta a adoção de protocolo para amenizar possíveis ocorrências de incidentes com energia ultrassônica 55 e a utilização de diques de borracha 90,91. Esse último é um dispositivo que isola o elemento dentário para o procedimento endodôntico e evita incidentes, como a aspiração e/ou deglutição de artefatos.

Como soluções apresentadas para prevenir os EA relacionados ao circuito de medicamentos, Skaar \& O’Connor 92 destacaram a necessidade de aumentar o conhecimento dos cirurgiões-dentistas em relação aos medicamentos prescritos e suas interações. Donaldson \& Goodchild 93 enfatizaram a importância da orientação desses profissionais quanto ao uso de antagonistas farmacológicos para ajudar a mitigar emergências médicas induzidas por medicamentos.

Por sua vez, Noguerado et al. ${ }^{94}$ propuseram um guia para a prescrição medicamentosa às grávidas e lactantes e Hussein et al. 95 sugeriram um conjunto de indicadores para melhorar a qualidade na prescrição. Importa ressaltar que muitos erros de medicamentos ocorrem devido a falhas que poderiam ser facilmente evitadas, entre as quais são exemplos: a baixa adesão a protocolos e a realização de prescrições ilegíveis 96 . As atividades clínicas em uma universidade devem representar o padrão-ouro do desempenho profissional 97 e a implantação de programas educacionais poderia beneficiar o desenvolvimento necessário de habilidades de prescrição do cirurgião-dentista 98,99.

Metodologias voltadas à melhoria da qualidade tendem a favorecer a segurança do paciente 29,97. A auditoria clínica, por exemplo, consiste em uma ferramenta útil principalmente quando: (i) é 
estruturada formal e continuamente, com horário regular de reuniões e eventos com permissão de comunicação direta vertical e horizontal; (ii) é realizado o treinamento de um número significativo de funcionários; (iii) é alinhada de acordo com as prioridades locais; (iv) há acompanhamento de todas as suas fases (registro, coleta de dados, análise de dados e relatório); (v) há monitoramento atempado de cada recomendação no plano de ação e sua conclusão se efetiva antes do próximo ciclo de auditoria a ser executado 100 .

Outra ferramenta disponível é a análise de risco. Para o caso de pacientes com necessidades motoras e/ou cognitivas que necessitam de cuidados específicos, Perea-Pérez et al. 57 propuseram uma análise de riscos própria. Essa considera os riscos relacionados aos pacientes e os associados aos profissionais e ao ambiente de saúde.

As notificações de incidentes constituem uma excelente fonte de aprendizagem organizacional e servem de substrato para a elaboração de estratégias e intervenções de melhoria da segurança do paciente 28 . Autores que utilizaram bases de dados mistas, ou seja, que envolveram notificações relativas às áreas de saúde em geral, sugeriram que um sistema de notificação específico para pacientes odontológicos poderia facilitar tanto a notificação quanto a posterior análise destes eventos 12 .

Faz-se necessário, entretanto, o desenvolvimento de políticas institucionais para reduzir barreiras que dificultam a notificação por parte dos profissionais 12,66,75 e o envolvimento do paciente e seus familiares, estimulando-os ao relato de danos 101. Torna-se oportuno, ainda, em âmbito mais abrangente dessas políticas, aumentar a conscientização da população acerca do problema 102.

Muitos EA poderiam ser evitados mediante a manutenção de prontuários precisos 103 . O consentimento informado, anexado aos registros do prontuário, comprovou ser valioso por colocar o paciente na centralidade das decisões terapêuticas 104. Além disso, agregar ao prontuário fotografias e radiografias que registram situações relativas à ocorrência de incidentes, bem como resultados de exames laboratoriais, podem ser de grande utilidade na análise e avaliação de EA 41.

Todavia, a segurança do paciente em Odontologia é multifatorial e complexa ${ }^{9}$. As soluções apresentadas pressupõem forte atuação organizacional e trabalho em equipe. Tais condições estruturantes nem sempre são favoráveis, seja pelas características inerentes à prestação do cuidado odontológico em si, seja por outros fatores organizacionais.

Fica, portanto, explícita a necessidade de envidar esforços na pesquisa em segurança do paciente na Odontologia, com o objetivo de auxiliar a sistematização e organização da prestação dos cuidados e colaborar com a redução dos EA na área.

\section{Limitações do estudo}

A revisão integrativa constitui uma ferramenta importante por permitir a análise da literatura de forma ampla e sistemática. Entretanto, os termos da busca nas bases de dados bibliográficos contemplaram apenas os idiomas inglês, português e espanhol, o que pode ter reduzido o número de artigos capturados. Outra limitação relacionada aos termos usados na busca diz respeito a não inclusão do termo MeSH adverse events, amplamente utilizado para indexar publicações na área de segurança do paciente. Para mitigar essa questão, os autores ampliaram a busca para além dos termos MeSH usados, incluindo o termo patient safety em títulos e resumos, o que propiciou capturar estudos publicados a partir de 2005. A utilização de apenas três bases de dados bibliográficos pode também ter incorrido em viés, embora os autores considerem que as mesmas reúnem produção científica expressiva da área da saúde. Na busca bibliográfica, 13 artigos foram excluídos. Desses, 7 não apresentaram resumo disponível e 6 eram inacessíveis. Logo, potenciais achados desses estudos não foram incluídos nesta revisão. Na tentativa de minimizar esses vieses, nove artigos foram incluídos com base na análise das referências dos artigos capturados.

\section{Conclusão}

As publicações demonstraram que a Odontologia está evoluindo no sentido de um melhor conhecimento em relação aos aspectos da segurança do paciente, principalmente nos países desenvolvidos. A possibilidade de reunir estudos com metodologias e objetivos diversos contribuiu para descrever 
sua atual inserção na temática, e possibilitou identificar uma gama de proposições para a melhoria da segurança do cuidado.

A complexidade do atendimento em saúde compreende fatores inerentes ao ambiente e à ação humana que, em Odontologia, amplificam as chances de ocorrência de EA mediante uma atuação solitária e fragmentada. A conformação de um ambiente favorável à segurança do paciente odontológico exige o engajamento da universidade, indústria, gestão dos serviços, juntamente com profissionais do atendimento direto, pacientes e seus familiares. Nesse sentido, os estudos qualitativos, apesar de poucos nesta revisão, se mostraram bastante úteis.

Como em outros ofícios que são frutos diretos do trabalho humano, o resultado do atendimento é dependente do profissional executante. Assim, a capacitação e o treinamento, a ergonomia, o tempo de atendimento suficiente, além de insumos operacionais apropriados, foram apontados como primordiais para aproximar o trabalho real do idealizado e reduzir o risco da ocorrência de danos aos pacientes em Odontologia.

Ao observar a evolução das pesquisas de acordo com os componentes do ciclo proposto pela OMS, verificou-se que os estudos dedicados à primeira fase, ou seja, medir o dano, não constituíram a maioria. Os principais EA em Odontologia foram identificados: lesões em tecidos duros e moles da cavidade oral, com destacada atenção à possibilidade de exodontias trocadas; alergias, complicações anestésicas e infecções, circunstâncias que, se agravadas, podem inclusive levar ao óbito. Compreender as causas da ocorrência de EA e identificar soluções para evitá-los foram consonantes a muitos estudos, representando o esforço para mitigar o problema.

Dentre os fatores contribuintes descritos, listou-se: falhas no planejamento e na gestão do cuidado, comunicação ineficaz, uso inadequado de tecnologias, deficiências na formação, e cultura de segurança fragilizada. As propostas de instrumentos e métodos apresentadas para diminuir o impacto desses problemas carecem de estudos de avaliação adicionais.

Por fim, apenas dois estudos classificados na última fase do ciclo transpõem para a prática medidas avaliadas como de impacto positivo para a melhoria da segurança do paciente. Esses achados confirmam a inserção da Odontologia na área, mas evidenciam um longo caminho a percorrer, denotando campo fértil para a realização de pesquisas a fim de contribuir para melhorar a qualidade e a segurança no cuidado odontológico.

\section{Colaboradores}

C. D. T. S. O. Corrêa e C. T. Reis contribuíram na elaboração e execução da metodologia, bem como na construção e revisão do artigo. P. Sousa contribuiu com a análise dos dados e revisão final do artigo.

\section{Informações adicionais}

ORCID: Claudia Dolores Trierweiler Sampaio de Oliveira Corrêa (0000-0001-9323-9720); Paulo Sousa (0000-0001-9502-6075); Claudia Tartaglia Reis (0000-0002-5392-9281).

\section{Referências}

1. Organização Mundial da Saúde. Estrutura conceitual da Classificação Internacional sobre Segurança do Doente. Relatório técnico final. Lisboa: Organização Mundial da Saúde; 2011.

2. Trindade L, Lage MJW. A perspectiva histórica e principais desenvolvimentos da segurança do paciente. In: Sousa P, Mendes W, organizadores. Segurança do paciente: conhecendo os riscos nas organizações de saúde. 2a Ed. Rio de Janeiro: Coordenação de Desenvolvimento EducacionaI e EAD, Escola Nacional de Saúde Pública Sergio Arouca, Fundação Oswaldo Cruz; 2019. p. 41-58.

3. Institute of Medicine Committee on Quality of Health Care in America; Kohn LT, Corrigan JM, Donaldson MS, editors. To err is human: building a safer health system. Washington DC: National Academies Press; 2000. 
4. Institute of Medicine Committee on Quality of Health Care in America. Crossing the quality chasm: a new health system for the $21^{\text {st }}$ century. Washington DC: National Academies Press; 2001.

5. World Health Organization. Assessing and tackling patient harm: a methodological guide for data-poor hospitals. Geneva: World Health Organization; 2010.

6. Caldas BN, Sousa P, Mendes W. Investigação/ pesquisa em segurança do paciente. In: Sousa P, Mendes W, organizadores. Segurança do paciente: criando organizações de saúde seguras. 2a Ed. Rio de Janeiro: Coordenação de Desenvolvimento EducacionaI e EAD, Escola Nacional de Saúde Pública Sergio Arouca, Fundação Oswaldo Cruz; 2019. p. 201-23.

7. Mendes W, Martins M, Rozenfeld S, Travassos C. The assessment of adverse events in hospitals in Brazil. Int J Qual Health Care 2009; 21:279-84.

8. Hughes A, Davies L, Hale R, Gallagher JE. Adverse incidents resulting in exposure to body fluids at a UK dental teaching hospital over a 6-year period. Infect Drug Resist 2012; 5: 155-61.

9. Yamalik N, Perea-Pérez B. Patient safety and dentistry: what do we need to know? Fundamentals of patient safety, the safety culture and implementation of patient safety measures in dental practice. Int Dent J 2012; 62:189-96.

10. Bailey E, Tickle M, Campbell S. Patient safety in primary care dentistry: where are we now? Br Dent J 2014; 217:339-44.

11. Viola NV, Oliveira ACM, Dota EAV. Ferramentas automatizadas: o reflexo da evolução tecnológica na Odontologia. Rev Bras Odontol 2011; 68:76-80.

12. Thusu S, Panesar S, Bedi R. Patient safety in dentistry - state of play as revealed by a national database of errors. Br Dent J 2012; 213:E3.

13. Perea-Pérez B, Santiago-Sáez A, García-Marín F, Labajo-González E, Villa-Vigil A. Patient safety in dentistry: dental care risk management plan. Med Oral Patol Oral Cir Bucal 2011; 16:e805-9.

14. Thomas EJ, Petersen LA. Measuring errors and adverse events in health care. J Gen Intern Med 2003; 18:61-7.

15. Murff HJ, Patel VL, Hripcsak G, Bates DW. Detecting adverse events for patient safety research: a review of current methodologies. J Biomed Inform 2003; 36:131-43.

16. Perea-Pérez B. Seguridad del paciente y odontología. Cient Dent 2010; 8:9-15.

17. Speers RD, McCulloch CA. Optimizing patient safety: can we learn from the airline industry? J Can Dent Assoc 2014; 80:e37.

18. O'Brien T. Reducing harm in healthcare systems. Prim Dent J 2015; 4:34-7.

19. Bagg J, Welbury R. The Francis Report: why it matters to the dental team. Dent Update 2015; 42:206-9.
20. Castillo HPC. Seguridad del paciente en los servicios de estomatología. Rev ADM 2016; 73:155-62.

21. Piccinni C, Gissi DB, Gabusi A, Montebugnoli L, Poluzzi E. Paraesthesia after local anaesthetics: an analysis of reports to the FDA Adverse Event Reporting System. Basic Clin Pharmacol Toxicol 2015; 117:52-6.

22. Parker W, Estrich CG, Abt E, Carrasco-Labra A, Waugh JB, Conway A, et al. Benefits and harms of capnography during procedures involving moderate sedation: a rapid review and meta-analysis. J Am Dent Assoc 2018; 149:3850.e2.

23. Kalenderian E, Walji MF, Tavares A, Ramoni RB. An adverse event trigger tool in dentistry: a new methodology for measuring harm in the dental office. J Am Dent Assoc 2013; 144:80814.

24. Mettes T, Bruers J, van der Sanden W, Wensing M. Patient safety in dental care: a challenging quality issue? An exploratory cohort study. Acta Odontol Scand 2013; 71:1588-93.

25. Hiivala N, Mussalo-Rauhamaa H, Murtomaa H. Patient safety incidents reported by Finnish dentists: results from an internet-based survey. Acta Odontol Scand 2013; 71:1370-7.

26. Lee HH, Milgrom P, Starks H, Burke W. Trends in death associated with pediatric dental sedation and general anesthesia. Paediatr Anaesth 2013; 23:741-6.

27. Perea-Pérez B, Labajo-González E, SantiagoSáez A, Albarrán-Juan E, Villa-Vigil A. Analysis of 415 adverse events in dental practice in Spain from 2000 to 2010. Med Oral Patol Oral Cir Bucal 2014; 19:500-5.

28. Jonsson L, Gabre P. Adverse events in public dental service in a Swedish county: a survey of reported cases over two years. Swed Dent J 2014; 38:151-60.

29. Akifuddin S, Khatoon F. Reduction of complications of local anaesthesia in dental healthcare setups by application of the sixsigma methodology: a statistical quality improvement technique. J Clin Diagn Res 2015; 9:ZC34-8.

30. Christiani JJ, Rocha MT, Valsecia M. Seguridad del paciente en la práctica odontológica. Acta Odontol Colomb 2015; 5:21-32.

31. Obadan EM, Ramoni RB, Kalenderian E. Lessons learned from dental patient safety case reposts. J Am Dent Assoc 2015; 146:318-26.

32. Hebballi NB, Ramoni R, Kalenderian E, Delattre VF, Stewart DC, Kent K, et al. The dangers of dental devices as reported in the Food and Drug Administration Manufacturer and User Facility Device Experience Database. J Am Dent Assoc 2015; 146:102-10.

33. Hiivala N, Mussalo-Rauhamaa H, Tefke HL, Murtomaa H. An analysis of dental patient safety incidents in a patient complaint and healthcare supervisory database in Finland. Acta Odontol Scand 2016; 74:81-9. 
34. Maramaldi P, Walji MF, White J, Etolue J, Kahn M, Vaderhobli R, Kwatra J, et al. How dental team members describe adverse events. J Am Dent Assoc 2016; 147:803-11.

35. Ensaldo-Carrasco E, Suarez-Ortegon MF, Carson-Stevens A, Cresswell K, Bedi R, Sheikh A. Patient safety incidents and adverse events in ambulatory dental care: a systematic scoping review. J Patient Saf 2016; (Online ahead of print).

36. Tokede O, Walji M, Ramoni R, Rindal DB, Worley D, Hebballi N, et al. Quantifying dental office-originating adverse events: the Dental Practice Study methods. J Patient Saf 2017; (Online ahead of print).

37. Corrêa CDTSO, Mendes W. Proposal of a trigger tool to assess adverse events in dental care. Cad Saúde Pública 2017; 33:e00053217.

38. Osegueda-Espinosa AA, Sánchez-Pérez L, Perea-Pérez B, Labajo-González E, Acosta-Gio AE. Dentists survey on adverse events during their clinical training. J Patient Saf 2017; (Online ahead of print).

39. Huertas MF, Gonzalez J, Camacho S, Sarralde AL, Rodríguez A. Analysis of the adverse events reported to the office of the clinical director at a dental school in Bogotá, Colombia. Acta Odontol Latinoam 2017; 30:19-25.

40. Pesántez Alvarado JM, Camacho Ladino JM, Rodríguez Ciódaro A, Camacho Peña SP, Sarralde Delgado AL, Castro Haiek DE, et al. Análisis de los eventos desfavorables como resultado de la atención en cirugía oral. Univ Odontol 2017; 36(77). https://revistas.javeria na.edu.co/index.php/revUnivOdontologica/ article/view/21137.

41. Pérez Gómez W, Pita Bejarano AM, Ramos Vargas CA, González Moncada J, Güiza Cristancho EH, Rodríguez Ciódaro A. Análisis de los eventos adversos em el área de rehabilitación oral de la Facultad de Odontología de la Pontificia Universidad Javeriana Bogotá. Univ Odontol 2017; 36(77). https://revistas.javeria na.edu.co/index.php/revUnivOdontologica/ article/view/20829.

42. Kalenderian E, Obadan-Udoh E, Yansane A, Kent K, Hebballi NB, Delattre V, et al. Feasibility of electronic health record-based triggers in detecting dental adverse events. Appl Clin Inform 2018; 9:646-53.

43. Stahl JM, Mack K, Cebula S, Gillingham BL. Dental patient safety in the military health system: joining medicine in the journey to high reliability. Mil Med 2019; 185:e262-8.

44. Renton T, Sabbah W. Review of never and serious events related to dentistry 2005-2014. Br Dent J 2016; 221:71-9.

45. Black I, Bowie P. Patient safety in dentistry: development of a candidate 'never event' list for primary care. Br Dent J 2017; 222:782-8.

46. Ensaldo-Carrasco E, Carson-Stevens A, Cresswell K, Bedi R, Sheikh A. Developing agreement on never events in primary care dentistry: an international eDelphi study. Br Dent J 2018; 224:733-40.
47. Christiani JJ, Rocha MT. Percepción de la seguridad del paciente en odontología. Rev Asoc Odontol Argent 2015; 103:154-9.

48. Bailey E. Contemporary views of dental practitioners' on patient safety. Br Dent J 2015; 219:535-40.

49. Marchon SG, Mendes WV. Segurança do paciente na atenção primária à saúde: revisão sistemática. Cad Saúde Pública 2014; 30: 1815-35.

50. Mendonça JMD, Lyra Jr. DP, Rabelo JS, Siqueira JS, Balisa-Rocha BJ, Gimenes FRE, et al. Analysis and detection of dental prescribing errors at primary health care units in Brazil. Pharm World Sci 2010; 32:30-5.

51. Donaldson M, Goodchild JH, Epstein JB. Sugar content, cariogenicity, and dental concerns with commonly used medications. J Am Dent Assoc 2015; 146:129-33.

52. Donaldson M, Goodchild JH, Ziegler J. Dental considerations for patients taking weight-loss medications. J Am Dent Assoc 2014; 145:70-4.

53. Donaldson M, Touger-Decker R. Dietary supplement interactions with medications used commonly in dentistry. J Am Dent Assoc 2013; 144:787-94.

54. Donaldson M, Touger-Decker R. Vitamin and mineral supplements: friend or foe when combined with medications? J Am Dent Assoc 2014; 145:1153-8.

55. Gluskin AH, Ruddle CJ, Zinman EJ. Thermal injury through intraradicular heat transfer using ultrasonic devices: precautions and practical preventive strategies. J Am Dent Assoc 2005; 136:1286-93.

56. Martín-Cameán A, Jos A, Mellado-García P, Iglesias-Linares A, Solano E, Cameán AM. In vitro and in vivo evidence of the cytotoxic and genotoxic effects of metal ions released by orthodontic appliances: a review. Environ Toxicol Pharmacol 2015; 40:86-113.

57. Perea-Pérez B, Labajo-González E, BratosMurillo M, Santiago-Sáez A, Albarrán-Juan E, Villa-Vigil A. The clinical safety of disabled patients: proposal for a methodology for analysis of health care risks and specific measures for improvement. Med Oral Patol Oral Cir Bucal 2013; 18:e251-6.

58. Tan GM. A medical crisis management simulation activity for pediatric dental residents and assistants. J Dent Educ 2011; 75:782-90.

59. Raja S, Rajagopalan CF, Patel J, Van Kanegan $K$. Teaching dental students about patient communication following an adverse event: a pilot educational module. J Dent Educ 2014; 78:757-62.

60. Palmer JC, Blanchard JR, Jones J, Bailey E. Attitudes of dental undergraduate students towards patient safety in a UK dental school. Eur J Dent Educ 2019; 23:127-34.

61. Al-Surimi K, Al Ayadi H, Salam M. Female dental students' perceptions of patient safety culture: a cross sectional study at a middle eastern setting. BMC Med Educ 2018; 18:301. 
62. Al Blaihed RM, Al Saeed MI, Abuabat AA, Ahsan SH. Incident reporting in dentistry: clinical supervisor's awareness, practice and perceived barriers. Eur J Dent Educ 2018; 22:e408-18.

63. Reis CT. Cultura de segurança em organizações de saúde. In: Sousa P, Mendes W, organizadores. Segurança do paciente: criando organizações de saúde seguras. 2a Ed. Rio de Janeiro: Coordenação de Desenvolvimento EducacionaI e EAD, Escola Nacional de Saúde Pública Sergio Arouca, Fundação Oswaldo Cruz; 2019. p. 77-109.

64. Pemberton MN, Ashley MP, Shaw A, Dickson S, Saksena A. Measuring patient safety in a UK dental hospital: development of a dental clinical effectiveness dashboard. Br Dent J 2014; 217:375-8.

65. Nelson TM, Xu Z. Pediatric dental sedation: challenges and opportunities. Clin Cosmet Investig Dent 2015; 7:97-106.

66. Leong P, Afrow J, Weber HP, Howell H. Attitudes toward patient safety standards in U.S. dental schools: a pilot study. Dent Educ 2008; 72:431-7.

67. Yamalik N, Van Dijk W. Analysis of the attitudes and needs/demands of dental practitioners in the field of patient safety and risk management. Int Dent J 2013; 63:291-7.

68. Ramoni R, Walji MF, Tavares A, White J, Tokede O, Vaderhobli R, et al. Open wide: looking into the safety culture of dental school clinics. J Dent Educ 2014; 78:745-56.

69. Ali I, Singla A, Gupta R, Patthi B, Dhama K, Niraj LK, et al. Psychometric utility in determining dental organizational attribute: a cross sectional study in Ghaziabad, India. J Clin Diagn Res 2017; 11:ZC52-5.

70. Al Sweleh FS, Al Saedan AM, Al Dayel OA. Patient safety culture perceptions in the college of dentistry. Medicine (Baltimore) 2018; 97:e9570.

71. Chew BKS, Sim DZ, Pau A. Dentists' perceptions of the meaning and promotion patient safety: a qualitative study. Oral Health Dent Manag 2018; 17:1-5.

72. Cheng H-C, Yen AM, Lee Y-H. Factors affecting patient safety culture among dental healthcare workers: a nationwide cross-sectional survey. J Dent Sci 2019; 14:263-8.

73. Choi EM, Mun SJ, Chung WG, Noh HJ. Relationships between dental hygienists' work environment and patient safety culture. BMC Health Serv Res 2019; 19:299.

74. Nainar SMH. Adverse events during dental care for children: implications for practitioner health and wellness. Pediatr Dent 2018; 40:323-6.

75. Renton T, Master S. The complexity of patient safety reporting systems in UK dentistry. $\mathrm{Br}$ Dent J 2016; 221:517-24.

76. Renouard F, Amalberti R, Renouard E. Are "human factors" the primary cause of complications in the field of implant dentistry? Int J Oral Maxillofac Implants 2017; 32:e55-e61.
77. Vila-Sierra LA, Salcedo-Salgado JD, Fernández-Roncallo YY, Narváez-Barandica MM. Grado de implementación del proceso de seguridad en el paciente en IPS odontológicas públicas y privadas en Santa Marta. Rev Gerenc Políticas Salud 2017; 16:116-25.

78. Knepil GJ, Harvey CT, Beech AN. Marking the skin for oral surgical procedures: improving the WHO checklist. Br J Oral Maxillofac Surg 2013; 51:413-5.

79. Cullingham P, Saksena A, Pemberton MN. Patient safety: reducing the risk of wrong tooth extraction. Br Dent J 2017; 222:759-63.

80. Bennett JD, Kramer KJ, Bosack RC. How safe is deep sedation or general anesthesia while providing dental care? J Am Dent Assoc 2015; 146:705-8.

81. Robert RC, Patel CM. Oral surgery patient safety concepts in anesthesia. Oral Maxillofac Surg Clin North Am 2018; 30:183-93.

82. Perea-Pérez B, Santiago-Sáez A, García-Marín F, Labajo González E. Proposal for a 'surgical checklist' for ambulatory oral surgery. Int J Oral Maxillofac Surg 2011; 40:949-54.

83. Bailey E, Tickle M, Campbell S, O’Malley L. Systematic review of patient safety interventions in dentistry. BMC Oral Health 2015; $15: 152$.

84. Schmitt CM, Buchbender M, Musazada S, Bergauer B, Neukam FW. Evaluation of staff satisfaction after implementation of a surgical safety checklist in the ambulatory of an oral and maxillofacial surgery department and its impact on patient safety. J Oral Maxillofac Surg 2018; 76:1616-39.

85. Wright S, Ucer TC, Crofts G. The adaption and implementation of the WHO surgical safety checklist for dental procedures. Br Dent J 2018; 225:727-9.

86. Christiani JJ, Rocha MT. Checklist quirúrgico en odontología: componente clave en la seguridad del paciente. Rev Asoc Odontol Argent 2019; 107:33-7.

87. Beddis HP, Davies SJ, Budenberg A, Horner K, Pemberton MN. Temporomandibular disorders, trismus and malignancy: development of a checklist to improve patient safety. Br Dent J 2014; 217:351-5.

88. Nenad MW, Halupa C, Spolarich AE, Gurenlian JR. A dental radiography checklist as a tool for quality improvement. J Dent Hyg 2016; 90:386-93.

89. Díaz-Flores-García V, Perea-Pérez B, LabajoGonzález E, Santiago-Sáez A, Cisneros-Cabello R. Proposal of a "checklist" for endodontic treatment. J Clin Exp Dent 2014; 6:e104-9.

90. Madarati A, Abid S, Tamimi F, Ezzi A, Sammani A, Shaar MBAA, et al. Dental-dam for infection control and patient safety during clinical endodontic treatment: preferences of dental patients. Int J Environ Res Public Health 2018; 15:E2012. 
91. Asmarz HY, Benfati CAM, Bolan M. Accidental ingestion of a dental irrigation needle: a case report. Eur Arch Paediatr Dent 2019; 20:123-6.

92. Skaar DD, O'Connor H. Using the Beers criteria to identify potentially inappropriate medication use byolder adult dental patients. J Am Dent Assoc 2017; 148:298-307.

93. Donaldson M, Goodchild JH. Pharmacological reversal agents in dental practice: keys to patient safety. Compend Contin Educ Dent 2016; 37:681-7.

94. Noguerado M, Perea B, Labajo E, Santiago A, García F. Seguridad del paciente: prescripción de fármacos enodontología a mujeres embarazadas y en período de lactancia. Cient Dent 2011; 8:51-60.

95. Hussein RJ, Krohn R, Kaufmann-Kolle P, Willms G. Quality indicators for the use of systemic antibiotics in dentistry. Z Evid Fortbild Qual Gesundhwes 2017; 122:1-8.

96. Perea-Pérez B, Labajo-González E, AcostaGío AE, Yamalik N. Eleven basic procedures/ practices for dental patient safety. J Patient Saf $2015 ; 16: 36-40$

97. Rivera-Mendoza F, Acevedo-Atala C, PereaPérez B, Labajo-González E, Fonseca GM. Análisis causa-raíz sobre evento adverso producido en la Clínica Odontológica Docente Asistencial, Facultad de Odontología, Universidad de La Frontera, Chile. Int J Odontostomatol 2017; 11:207-16.

98. Guzmán-Álvarez R, Medeiros M, Lagunes LR, Campos-Sepúlveda A. Knowledge of drug prescription in dentistry students. Drug Healthc Patient Saf 2012; 4:55-9.
99. Mahmood A, Tahir MW, Abid A, Ullah MS, Sajjid M. Knowledge of drug prescription in dental students of Punjab Pakistan. Pakistan Journal of Medical and Health Sciences 2018; 12:232-7.

100. Ashley MP, Pemberton MN, Saksena A, Shaw A, Dickson S. Improving patient safety in a UK dental hospital: long-term use of clinical audit. Br Dent J 2014; 217:369-73.

101. Hiivala N, Mussalo-Rauhamaa H, Murtomaa H. Can patients detect hazardous dental practice? A patient complaint study. Int J Health Care Qual Assur 2015; 28:274-87.

102. Ibrahim NK, Alwafi HA, Sangoof SO, Turkistani AK, Alattas BM. Cross-infection and infection control in dentistry: knowledge, attitude and practice of patients attended dental clinics in King Abdulaziz University Hospital, Jeddah, Saudi Arabia. J Infect Public Health 2017; 10:438-45.

103. Hiivala N, Mussalo-Rauhamaa H, Murtomaa $H$. Patient safety incident prevention and management among Finnish dentists. Acta Odontol Scand 2013; 71:1663-70.

104. Robinson FG, Fields HW, Ness GM, Heinlein DJ, Gellin RG, Larsen PE. Development and implementation of a uniform dental schoolwide electronic treatment consenting process for patients. J Dent Educ 2018; 82:949-60. 
Abstract

Adverse events pose a serious problem for quality of healthcare. Dental practice is eminently invasive and involves close and routine contact with secretions; as such, it is potentially prone to the occurrence of adverse events. Various patient safety studies have been developed in the last two decades, but mostly in the hospital setting due to the organizational complexity, severity of the cases, and diversity and specificity of the procedures. The objective was to identify and explore studies on patient safety in dentistry. An integrative literature review was performed in MEDLINE via PubMed, Scopus via Portal Capes, and the Regional Portal of the Virtual Health Library, using the terms patient safety and dentistry in English, Spanish, and Portuguese, starting in 2000. The research cycle in patient safety was used, as proposed by the World Health Organization to classify studies. We analyzed 91 articles. The most common adverse events were allergies, infections, diagnostic delay or failure, and technical error. Measures to mitigate the problem highlight the need to improve communications, encourage reporting, and search for tools to assist the management of care. The authors found a lack of studies on implementation and assessment of the impact of proposals for improvement. Dentistry has made progress in patient safety but still needs to transpose the results into practice, where efforts are crucial to prevent adverse events.

Patient Safety; Dentistry; Quality of Health Care; Adverse Event

\section{Resumen}

Los eventos adversos constituyen un grave problema relacionado con la calidad del cuidado en la salud. La práctica odontológica, por ser eminentemente invasiva e implicar contacto intimo $y$ rutinario con secreciones, es potencialmente propicia para la ocurrencia de esos eventos. Diversos estudios en seguridad del paciente se desarrollaron en las dos últimas décadas, sin embargo, en mayor número en el ambiente hospitalario, en función de su complejidad organizativa, gravedad de casos, diversidad y especificidad de procedimientos. El objetivo fue identificar e investigar los estudios dirigidos a la seguridad del paciente odontológico. Se realizó una revisión integradora de la literatura con consulta al MEDLINE vía PubMed, Scopus vía Portal Capes y al Portal Regional de la Biblioteca Virtual de Salud, utilizándose los términos seguridad del paciente $y$ odontología en los idiomas inglés, español y portugués a partir de 2000. Se utilizó el ciclo de investigación en seguridad del paciente, propuesto por la Organización Mundial de la Salud para clasificar los estudios incluidos. Se analizaron 91 artículos. Los eventos adversos más comunes estuvieron relacionados con las alergias, infecciones, retraso o fallo de diagnóstico y con el error de la técnica. Las medidas para mitigar el problema apuntaron la necesidad de una mejora de la comunicación, incentivos a la notificación y búsqueda de instrumentos para apoyar la gestión del cuidado. Se constató la carencia de estudios de implementación y evaluación de impacto de las propuestas de mejora. La Odontología evolucionó en el campo de la seguridad del paciente, pero todavía está lejos de trasladar resultados a la práctica, siendo importante aunar esfuerzos para prevenir eventos adversos en esta área.

Seguridad del Paciente; Odontología; Calidad de la Atención de Salud; Evento Adverso
Recebido em 08/Out/2019

Versão final reapresentada em 24/Jun/2020

Aprovado em 29/Jun/2020 